\title{
Identification keys to the Anopheles mosquitoes of South America (Diptera: Culicidae). II. Fourth-instar larvae
}

\author{
Maria Anice Mureb Sallum ${ }^{*}$, Ranulfo González Obando², Nancy Carrejo² and Richard C. Wilkerson 3,4,5
}

\begin{abstract}
Background: Accurate species identification of South American anophelines using morphological characters of the fourth-instar larva is problematic, because of the lack of up-to-date identification keys. In addition, taxonomic studies, employing scanning electron microscopy of the eggs and DNA sequence data, have uncovered multiple complexes of morphologically similar species, and resulted in the resurrection of other species from synonymy, mainly in the subgenus Nyssorhynchus. Consequently, the identification keys urgently need to be updated to provide accurate morphological tools to identify fourth-instar larvae of all valid species and species complexes.

Methods: Morphological characters of the fourth-instar larvae of South American species of the genus Anopheles were examined and employed to elaborate a fully illustrated identification key. For species for which no specimens were available, illustrations were based on published literature records.

Results: A fully illustrated key to the fourth-instar larvae of South American species of the genus Anopheles (Diptera: Culicidae) is presented. Definitions of the morphological terms used in the key are provided and illustrated.

Conclusions: Morphological identification of South American Anopheles species based on the fourth-instar larvae has been updated. Characters of the spiracular apparatus were determined useful for the identification of morphologically similar species, in the Strodei Group and some taxa in the Myzorhynchella Section. The single versus branched abdominal seta 6-IV used to differentiate Myzorhynchella species from other Nyssorhynchus species was shown to be variable in Myzorhynchella species. Also, the abdominal setae 1-IV,V of Anopheles atacamensis and Anopheles pictipennis were shown to be slightly serrate at the edges. Recognition of this character is important to avoid inaccurate identification of these species as members of the subgenus Anopheles.
\end{abstract}

Keywords: Anopheles, Morphology, Illustrations, Identification key, Fourth-instar larvae

\section{Background}

General introductory comments, distributions and species authors and publication dates are given in Part I [1] of this series of four articles. Despite the continuous interventions to control and eliminate malaria, this disease

\footnotetext{
*Correspondence: masallum@usp.br

${ }^{1}$ Departamento de Epidemiologia, Faculdade de Saúde Pública,

Universidade de São Paulo, Avenida Doutor Arnaldo 715, São Paulo, São Paulo CEP01246-904, Brazil

Full list of author information is available at the end of the article
}

remains an important cause of morbidity and mortality in endemic tropical and subtropical countries throughout the world. Malaria occurrence is affected by several factors including those of the parasites, human host, anopheline mosquitoes and environment [2]. Because of its intrinsic complexity, in order to reach an effective and sustainable control of malaria it is necessary to adopt an integrated approach delineated on the evidence of local characteristics of the disease and transmission dynamics [3]. Thus, the public health policy for malaria control demands interventions focused on the local anopheline vector species

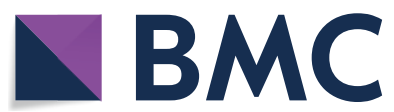

(c) The Author(s) 2020. This article is licensed under a Creative Commons Attribution 4.0 International License, which permits use, sharing, adaptation, distribution and reproduction in any medium or format, as long as you give appropriate credit to the original author(s) and the source, provide a link to the Creative Commons licence, and indicate if changes were made. The images or other third party material in this article are included in the article's Creative Commons licence, unless indicated otherwise in a credit line to the material. If material is not included in the article's Creative Commons licence and your intended use is not permitted by statutory regulation or exceeds the permitted use, you will need to obtain permission directly from the copyright holder. To view a copy of this licence, visit http://creativeco mmons.org/licenses/by/4.0/. The Creative Commons Public Domain Dedication waiver (http://creativecommons.org/publicdomain/ zero/1.0/) applies to the data made available in this article, unless otherwise stated in a credit line to the data. 
and empirical field-knowledge on the characteristics of the local populations behavior and ecology [4]. Different mosquito species exhibit distinct preferences for bloodfeeding on animals or humans, place where females take their blood-feeding, peak biting time, resting places and habitats. These biological characteristics of vector species need to be considered for the choice of an effective vector control intervention. It is important to note that vector control interventions need to be delineated for the local vector species, thus an accurate species identification is of vital importance for control, surveillance, and field malariology studies. Misidentification will cause error for a decision-making control programme that is based on metrics of transmission and local vector species [3]. Actions for vector control encompasses activities focused on the larval habitat to prevent the production of adult mosquitoes. This requires specific measures that are defined taken into consideration field-collected data of the vector population, and accurate identification of species and their habitats. The fastest, easiest, and cheapest way to identify field-collected mosquitoes for surveillance and control programmes is based on morphological characteristics. This activity is usually conducted by field-entomologists conducting mosquito collections, dissections of females in malaria endemic areas. A dichotomous morphological key is proposed with the purpose of providing a tool for identification of Anopheles species in South America based on the morphology of the fourth-instar larvae. The key includes major vectors, local vectors and species that have not been involved in the malaria transmission but can emerge and become dominant in human-dominated environments.

\section{Methods}

Morphological characters of the fourth-instar larvae of South American species of the genus Anopheles Meigen were examined and employed to construct a fully illustrated identification key. The primary types (holotypes and paratypes) and other field-collected specimens deposited in the Coleção Entomológica de Referência, Faculdade de Saúde Pública, Universidade de São Paulo, São Paulo, Brazil (FSP-USP), Museo de Entomología, Universidad del Valle, Santiago de Cali, Colombia (MUSENUV) and the US National Mosquito Collection, Smithsonian Institution, Washington, DC, USA (USNMC) were examined to discover characters to be used in the key based on larval morphology. For species that we could not access, drawings were based on published illustrations. Photomicrographs of relevant characters for the key were taken from the fourth-instar larval exuviae mounted on microscope slides and covered with a coverslip. Specimens were obtained either as field-collected larvae or progenies of field-collected females linked to either adults. The identification was based on the morphology of the male genitalia and females. Photomicrographs were taken with a digital Canon Eos T3i (Canon, USA) camera, attached to a Leitz Diaplan microscope, using the Helicon Focus software (https://www.heliconsoft.com/heliconsoft-produ cts/helicon-focus/) that was used to build single in-focus images by stacking multiple images of the same structure. These in-focus images were, then, employed to draw the line illustrations of the characters in CorelDRAW software (https://www.coreldraw.com/en/product/coreldraw/ essentials/?topNav=en). Except for one figure, illustrations are not to scale, but the proportions of the characters in the drawings are maintained. The morphological terminology employed in the key are defined and illustrated in accordance with Harbach \& Knight $[5,6]$. The key is modified after Faran \& Linthicum [7] and Forattini [8], with additional characters proposed herein. The species included in this Part II are listed in Table 1 of Sallum et al. [1] except for An. acanthotorynus Komp, 1937, An. albertoi Unti, 1941, An. arthuri Unti, 1941, An. bustamantei Galvão, 1955, An. canorii Flock \& Abonnenc, 1945, An. evandroi da Costa Lima, 1937, An. nigritarsis (Chagas, 1907), An. pseudomaculipes (Chagas in Peryassú, 1908), An. pseudopunctipennis levicastilloi Leví Castillo, 1944, An. pseudopunctipennis neghmei Mann, 1950, An. pseudopunctipennis noei Mann, 1950, An. pseudopunctipennis patersoni Alvarado \& Heredia, 1947, An. pseudopunctipennis rivadeneirai Leví Castillo, 1945, An. rachoui Galvão, 1952, An. sanctielii Senevet \& Abonnenc, 1938 and An. striatus Sant'Ana \& Sallum, 2016.

\section{Results and discussion}

\section{Glossary of morphological terms}

All mosquitoes pass through four larval instars (stadia, stages). As in all insects, mosquitoes have three body regions. These are well differentiated in mosquito larvae: the head (C), thorax (T) and abdomen (A) (Fig. 1). Mosquito larvae are metapneustic, meaning there is a single pair of respiratory openings caudally. Species of the subfamily Anophelinae Grassi, 1900, which includes the genus Anopheles Meigen, 1818, differ from the other culicid subfamily, Culicinae Meigen, 1818, in that the larval stages do not possess a respiratory siphon, but instead have paired spiracular openings on a clearly differentiated plate.

The larval cuticle (exoskeleton) bears a number of features of taxonomic utility. The most distinctive of these are the numbered, serially homologous (comparable between segments) setae that can almost always be directly compared to all other mosquito species. The setae can vary in number, form, and position (also referred to as chaetotaxy). Non-segmental structures, such as antennae and mouthparts, also have homologous numbered setae. Since setae are added with each of the four instars, the 

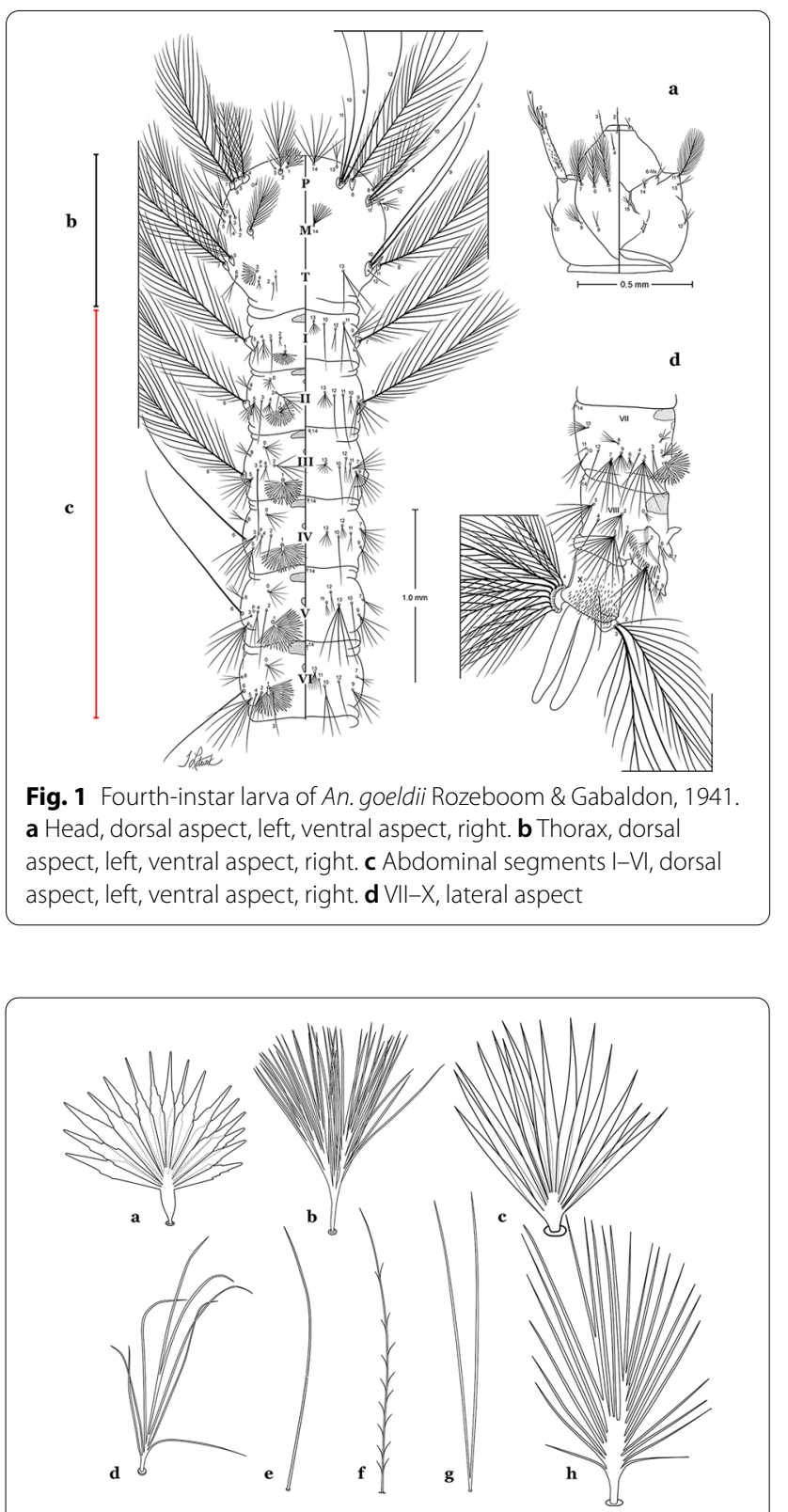

Fig. 2 Types of common setae on larval Anopheles. a Palmate with serrate margins. b Dendritic. c Palmate with smooth margins. d Branched seta with filamentous branches. e Simple. f Aciculate. $\mathbf{g}$ Bifurcate. $\mathbf{h}$ Plumose

numbering system is based on the last (4th) instar. Not all setae have taxonomic value. Therefore, we only discuss those that appear in our key, or may appear in other commonly used keys. Larvae usually possess 222 pairs of setae [5], 54 on the head (including antennae and mouthparts), 42 on the thorax and 126 on the abdomen. The primary types of setae, i.e. palmate, dendritic, branched, simple, aciculate, bifurcate, and plumose are illustrated (Fig. 2). The setae are designated with a number and a structure/ segment abbreviation, e.g. $2-\mathrm{C}$ is seta 2 on the head, and
1-A is seta 1 on the antenna. Any given seta on a segment is expressed in the singular even though there are two with the same number per segment, e.g. seta $2-C$ in the above example is expressed with a singular verb, i.e. "seta $2-\mathrm{C}$ is...." not "setae $2-\mathrm{C}$ are..... Singular is also used for the same numbered seta on different segments, e.g. seta 1 on abdominal segments II through VII would be "seta $1-\mathrm{II}-\mathrm{VII}$ is..... For different numbered setae on the same or multiple segment(s) the plural is used, e.g. setae 3 and 4 on abdominal segments II and III would be "setae 3,4II, III are..... On any given structure/segment the setae are numbered in ascending order beginning anteriorly or from the dorsomesal line. Species of the genus Anopheles can be differentiated from species of the genera Chagasia Cruz, 1906 and Bironella Theobald, 1905, also the Anophelinae, by characters of the spiracular apparatus. In Chagasia, the posterolateral spiracular lobes possess a fringe of setae laterally, and the anterior spiracular lobe is produced into an elongate process. Species of Anopheles and Bironella lack the fringe of setae and the anterior spiracular lobe is knob-like (see [9]). Note however that Bironella spp. occur in the Australasian Region, including Papua New Guinea, Solomon Islands, Bismarck and Queensland, Australia.

\section{Head}

The head is the most heavily sclerotized part of the body. It is usually longer than wide and, as in other culicids, is made up of various named sclerites (sclerotized plates). The head articulates with the thorax in such a way that is possible for larvae to rotate their heads up to $180^{\circ}$, resulting in great mobility while feeding. The head exhibits well-developed mandibles, maxillae, maxillary palpi and associated structures (for details see $[5,6]$ ). These are not utilized here but can be seen elsewhere in the literature. Anterolaterally there is a pair of antennae (A), which are made up of a very short scape and a long tubular structure formed by fusion of the antennal pedicel and flagellum. All insects have some variation of these three parts of the antenna (scape, pedicel and flagellum). On the antenna there are six pairs of setae, some of which are often called by informal names: antennal seta (1-A), a terminal antennal seta (4-A) and two setae in the form of a sabre (2-A and 3-A), one dorsal and the other ventral (Fig. 3). Seta 1-A is often used in identification since its branching and position can vary. Seta 4-A can be two- or threebranched, with symmetrical or asymmetrical branching.

The head has 15 pairs of setae, a number of which have taxonomic utility. These setae are often referred to by informal names. Head setae $2-\mathrm{C}, 3-\mathrm{C}$ and $4-\mathrm{C}$ are the clypeal setae. Setae 2-C and 3-C are located toward the most anterior part of the head and are called the anterior clypeal setae, with the lateral seta $(3-\mathrm{C})$ called external 


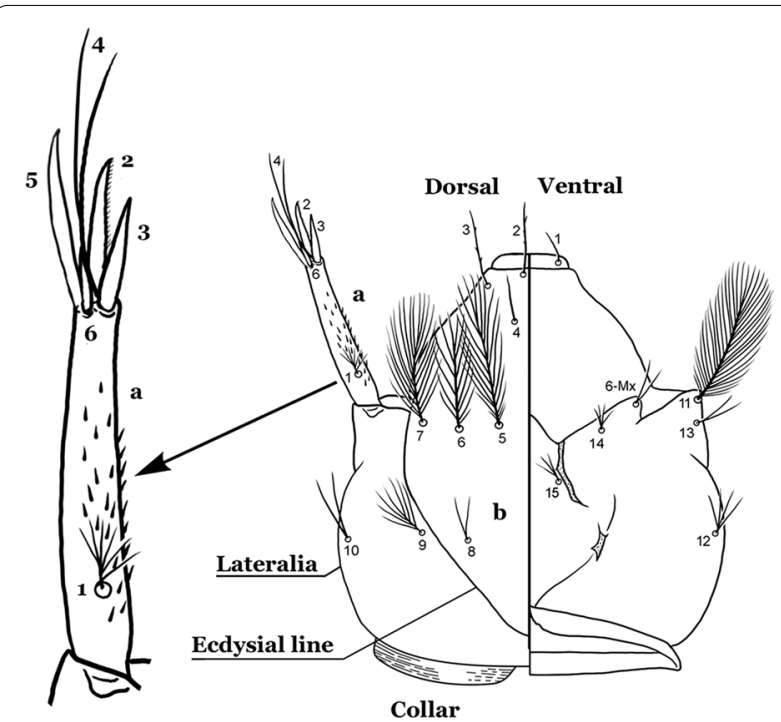

Fig. 3 Head of fourth-instar larva of An. goeldii. a Antenna. b Dorsal apotome

clypeal and the more mesal seta called the inner clypeal. These setae can be simple, aciculate, barbed, plumose, branched with simple branches, or dendritic, and can vary in length. The two seta $2-\mathrm{C}$ can be variably separated and are considered close when the distance between them is less than the distance between setae 2-C and 3-C on either side. If the distance between the two setae 2-C is equal or more than the distance between $2-\mathrm{C}$ and $3-\mathrm{C}$ they are considered well separated. The ratio between the distances between 2-C and 3-C on one of the sides with relation to the distance between the bases of the pair of 2-C, constitutes the clypeal index (distance between 2-C and 3-C on one side / distance separating setae 2-C [7]). Posterior to the anterior clypeal setae is the posterior clypeal seta (4-C), which can be single, bifurcate, forked, or multi-branched, short or long. Length is judged by how far forward the seta extends toward the bases of setae 2,3$\mathrm{C}$, and development compared to development of setae 2,3-C. Medially on the head are three pairs of setae often called the frontal setae: 5-C, 6-C and 7-C (5-7-C) (Fig. 3). They are generally long and extend at least past seta 4-C. They can be simple or branched, and sometimes appear simple but are slightly branched only apically. They usually occur in a line, but 7-C can be more anterior. Seta 8-C is posterolateral to 5-7-C. Setae 9-14-C are on an area called the lateralia (lat) (lateral and ventral areas of the head lateral to the ecdysial lines (Fig. 3). Of these, 9-C is located immediately lateral of the frontal ecdysial line and near $8-C$, while $10-C$ is lateral of $9-C$. Seta $11-C$ can also have taxonomic utility for the diagnosis of some species, and is found dorsolaterally near the base of the antenna.

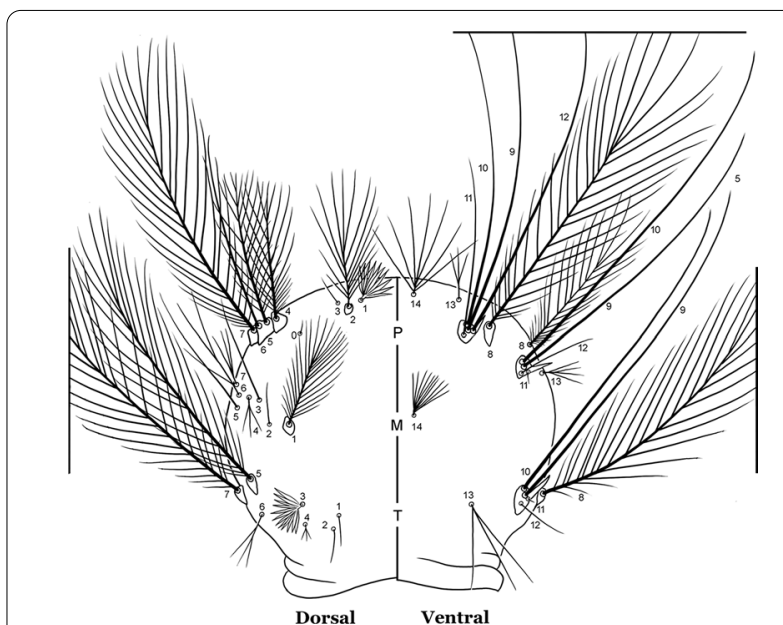

Fig. 4 Thorax of An. goeldii, dorsal aspect, left; ventral aspect, right. P, prothorax; M, mesothorax; T, metathorax

\section{Thorax}

The thorax is longer than wide and, as in all insects, is composed of three segments. In mosquito larvae the segments are not clearly differentiated. Using known setal groups as landmarks, one can recognize them even without distinct demarcations. They are the prothorax $(\mathrm{P})$ (nearest the head), the mesothorax (M) and the metathorax (T) (Fig. 4). There are 42 pairs of setae on the thorax, many with informal names. Near the midline on the prothorax are setae $1-3-P$, the submedian prothoracic group. These are often referred to their relative positions: internal (1-P), median (2-P) and external (3-P). Seta 1-P originates closest to the dorsomesal line and is generally branched or palmate. It is close to seta 2-P. Seta 3-P is usually simple and originates close to 1,2-P, which can share the same basal support plate or occur individually. These three setae are of great taxonomic utility. On the mesothorax and metathorax setae 1 and 2 (1-M,T and 2-M,T) can be closer to each other and well separated from seta 3 . The variable form of seta 3-T makes it useful in the identification of some species. Setae 9-12-P,M,T, the pro-, meso- and metathoracic pleural groups, originate on a common tubercle in a lateroventral position on all three segments. Some of the setae vary in form, size, and number of branches, which often makes them taxonomically useful.

\section{Abdomen}

As in all Culicidae, the abdomen is composed of $10 \mathrm{seg}$ ments, nine of them visible. Segments are identified by Roman numerals (I-X). The larva usually has the following pairs of setae: up to 12 on segment I, 15 on II-VII, seven on VIII, 13 on the spiracular apparatus and pecten, and four on X [5]. In the case of the spiracular apparatus and pecten, they are referenced by the letter $S$, to indicate that they are equivalent to the setae of the siphon in 


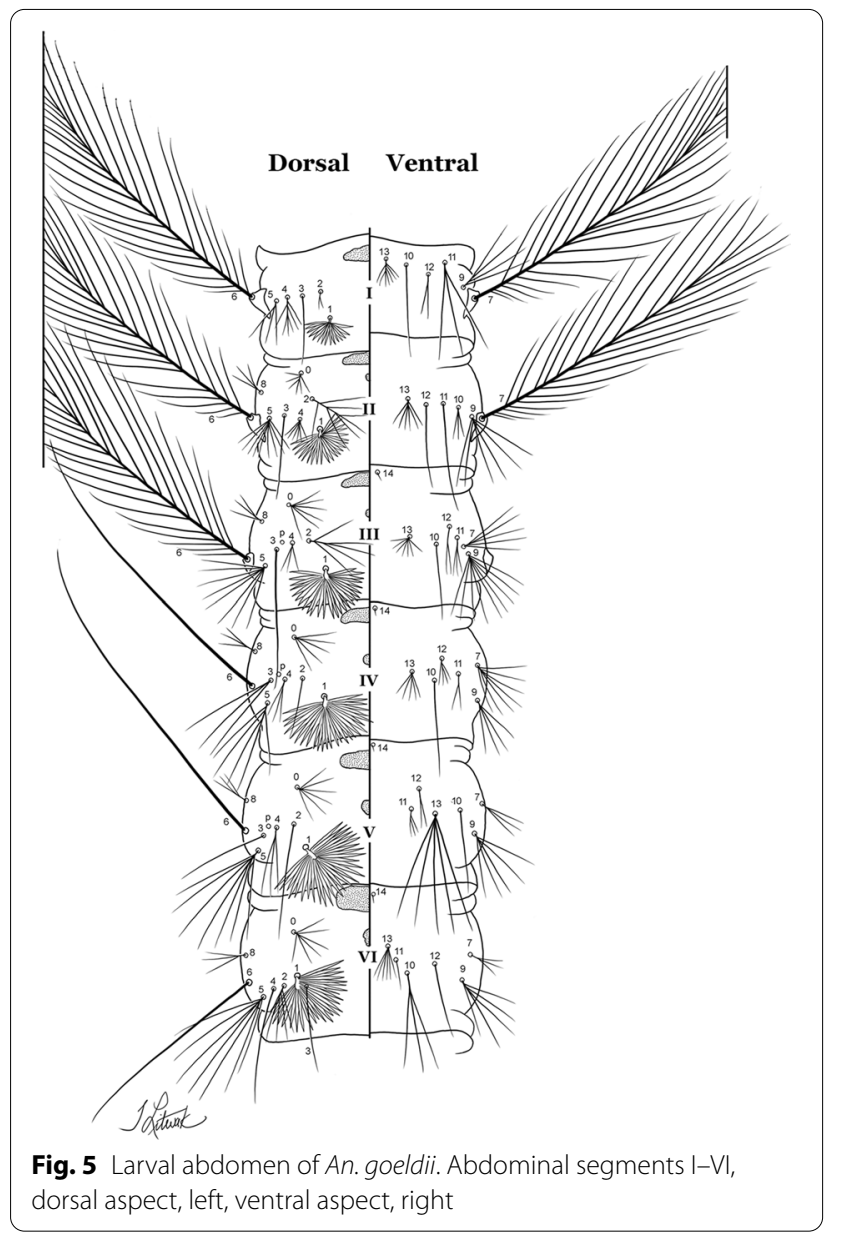

species of the subfamily Culicinae. The setal nomenclature starts with the number 0 (zero). Setae 8 and 14 are absent from segment I (Fig. 1). The following principal diagnostic setae are all dorsal or lateral. Seta 0-II-VII is the most anterior seta. It is usually poorly developed or inconspicuous, but its variability makes it useful for the identification of some species. Seta 1-I-VII is posterolateral, nearly equidistant between the midline and lateral margins (Fig. 5). In Anopheles, this seta, at least on segments III-VI, is usually palmate (form suggesting a palm frond or fan) or with filiform branches. In species of Chagasia, seta 1 is also palmate, but the leaflets are distinctive paddle-like structures with a long slender hair-like extension. Some species of Anopheles (found in tree holes) do not have palmate setae, or the palmate setae are not present on all segments. Palmate setae are variously developed, but the usual form is for the individual leaflets to have a short stem with many expanded leaflets. However, diagnostic variation includes having the margins smooth or strongly to moderately toothed, apices narrowed, filamentous, diamond-shaped, or truncate. Seta 6-I-VII is lateral, generally on a tubercle. These are informally

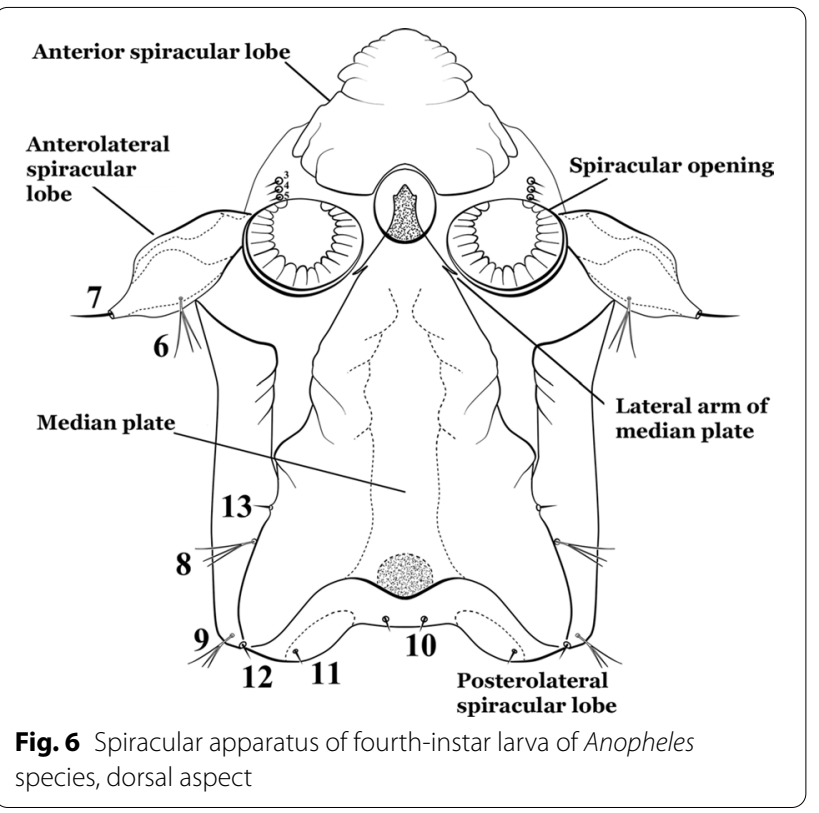

called lateral setae and are often the longest setae. Seta 6-IV-VII is usually simple or with a few branches but on segments I-III as they can be plumose. Segments VIII and $\mathrm{X}$ bear the pecten plate and the spiracular apparatus, both of which present various structures of taxonomic value. These include the anterior spiracular lobe, a median plate, two posterolateral spiracular lobes, and two anterolateral spiracular lobes (Fig. 6). The two spiracles are found behind the anterior spiracular lobe and on the sides of the anterior margin of the median plate. In species of the subgenus Stethomyia Theobald, 1902, the spiracular openings are well separated and located at the base of each anterolateral lobe. Usually, the median plate has lateral wings or arms of variable development and length that are utilized in the identification of some species or groups, especially in the subgenus $\mathrm{Nys}$ sorhynchus Blanchard, 1902 (Fig. 6). The posterolateral spiracular lobes can be rounded or include posterior projections, somewhat similar to spines, as observed in $A n$. pseudopunctipennis pseudopunctipennis Theobald, 1901. On either side of the spiracular apparatus is the pecten plate bearing pecten spines (Fig. 7), which is homologous in part with the siphon in the species of the Culicinae. It is a triangular plate with spines that resemble a comb. Frequently, variations in this structure are used for characterization of species of the subgenus Kerteszia Theobald, 1905; in some species the spines have an irregular arrangement, in others they have a regular arrangement of alternating long and short spines, whereas others exhibit equally-sized spines. There are 13 pairs of spiracular setae (1-13-S). Seta 1-S is generally the most developed and branched (with various simple branches). It is 


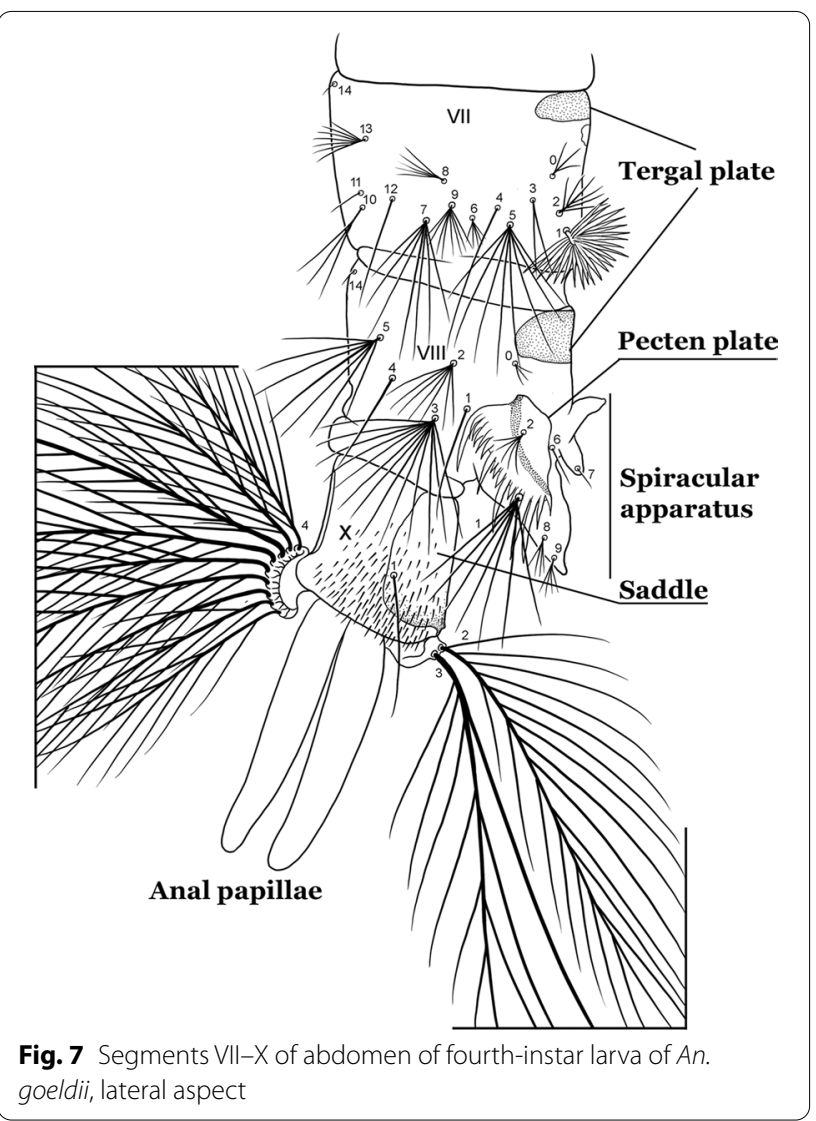

inserted posterior to the pecten plate below the posterolateral spiracular lobe. Seta 2-S is inserted at the base of the pecten plate. Setae 3-5-S, are generally small and indistinct, and 3-S is often only represented by an alveolus. These three setae are borne laterally on the anterior spiracular lobe. Setae 6-S and 7-S are on the proximal and distal anterolateral spiracular lobes, respectively. Setae 8-S and 9-S are on the proximal and distal lateral margins of the posterolateral spiracular lobe. Seta $10-\mathrm{S}$ is borne on the internal posterior margin, while 11-S and 12-S are found on the posterior border of the lobe (Fig. 7). Seta 13-S can be of taxonomic importance, it is borne medially on the anterior margin of the internal surface of the lobe. It is generally small and somewhat stout. In the case of An. darlingi Root, 1926, it is usually much longer than the dorsal length of the saddle.

The dichotomous identification key for the genus Anopheles, using morphological characters of the fourthinstar larva, includes species of the subgenera Anopheles Meigen, 1818, Kerteszia, Lophopodomyia Antunes, 1937, Nyssorhynchus and Stethomyia of the South America. Specimens of An. acanthotorynus, An. albertoi, An. arthuri, An. bustamantei, An. canorii, An. evandroi, An. nigritarsis, An. pseudomaculipes, An. pseudopunctipennis levicastilloi, An. pseudopunctipennis noei, An. pseudopunctipennis neghmei, An. pseudopunctipennis patersoni, An. pseudopunctipennis rivadeneirai, An. rachoui, An. sanctielii and An. striatus cannot be identified using this key. They are poorly known, and the original descriptions were based on the morphology of the eggs, or females, or males with no further association of all life stages. In addition, An. pseudopuntipennis encompasses six subspecies that are morphologically similar in all life stages, including the male genitalia. Thus, specimens of these subspecies will be identified as An. pseudopunctipennis. However, it is highly recommended to use geographical localities as additional information for identification. Anopheles striatus belongs to the Strodei Subgroup of the Oswaldoi Group. This subgroup includes Anopheles albertoi, Anopheles arthuri, Anopheles rondoni (Neiva \& Pinto, 1922), Anopheles striatus and Anopheles strodei. These species can be identified using DNA sequences of mitochondrial and nuclear genes [10-12], and morphological characters of the eggs, larvae, pupae, male genitalia, and females [13-15]. However, a detailed comparative morphological investigation will be necessary for description of all life stages and accurate species identification. In this key, specimens of species of the Strodei Subgroup will be identified as An. strodei/An. rondoni.

Key for the identification of species of the genus Anopheles of South America based on morphological characters of the fourth-instar larvae

1a Seta 1-III-VII small with filiform branches, not palmate, difficult to see without high magnification; anterolateral lobe of spiracular apparatus with an elongate process, ring-shaped; spiracles well separated, originating at base of anterolateral lobes (Fig. 8a).....

1b Seta 1-III-VII palmate, easily visible with low magnification (Fig. 8b); anterolateral lobe of spiracular apparatus without an elongate process; spiracles not separated as above (Fig. 6). . .4

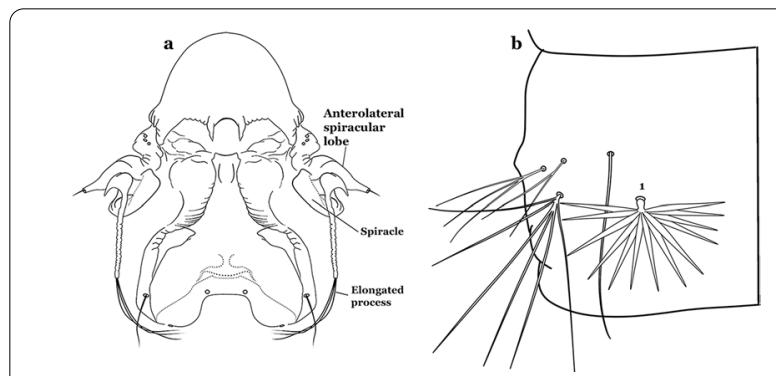

Fig. 8 a An. nimbus (Theobald, 1902), fourth-instar larva, spiracular apparatus. b An. albimanus Wiedemann, 1820, abdominal segment, dorsal aspect, showing palmate seta 1 
2a (1a) Seta 1-P single or with 2 or 3 apical branches (Fig. 9a). An. thomasi

2b Seta 1-P with 6-14 branches (Fig. 9b) ....3
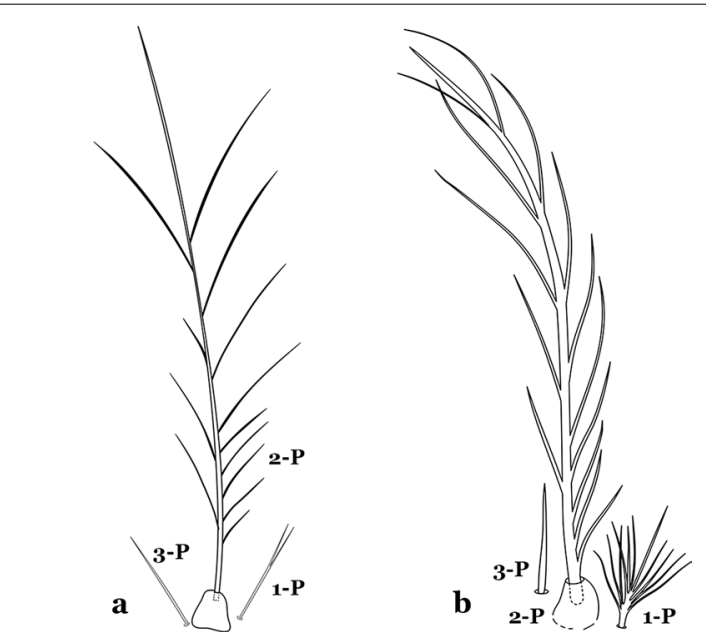

Fig. 9 Prothoracic setae 1-3-P. a An. thomasi Shannon, 1933. b An. nimbus

3a (2b) Seta 1-P with 6-8 branches (Fig. 10a).....An. kompi 3b Seta 1-P with 11-14 branches (Fig. 10b).....An. nimbus
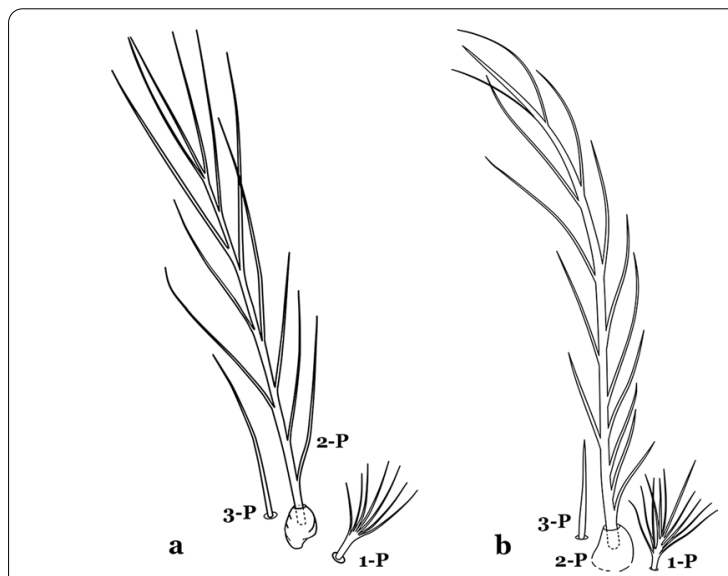

Fig. 10 Prothoracic setae 1-3-P. a An. kompi Edwards, 1930. b An. nimbus 4a (1b) Leaflets of seta 1-II-VII smooth-sided, apices variable (Fig. 11a, b). 5

4b Leaflets of seta 1-II-VII with slightly serrated margins, notched or distinctly serrate on apical third (Fig. 11c, d)

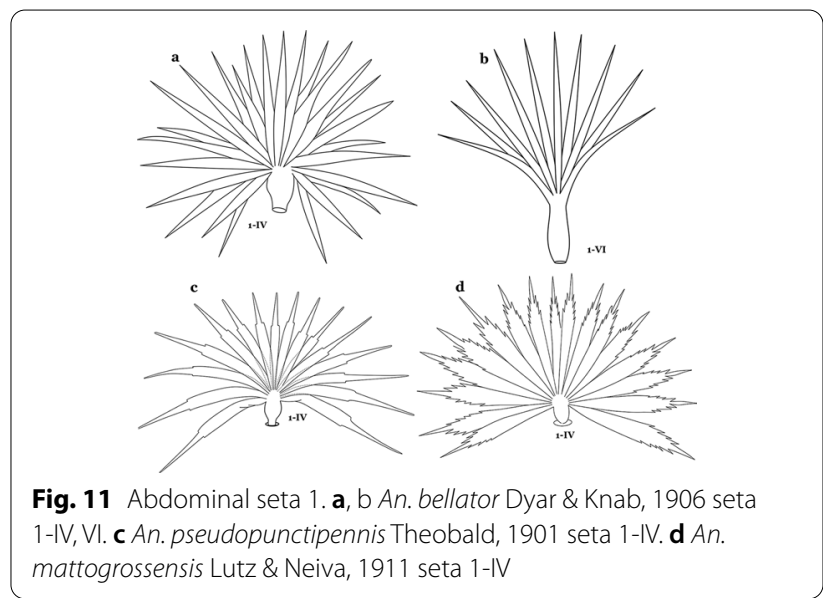

5a (4a) Setae 5-7-C single, double or branched apically, never plumose (Fig. 12a, b).

5b Setae 5-7-C plumose (Fig. 12c, d) .............................17

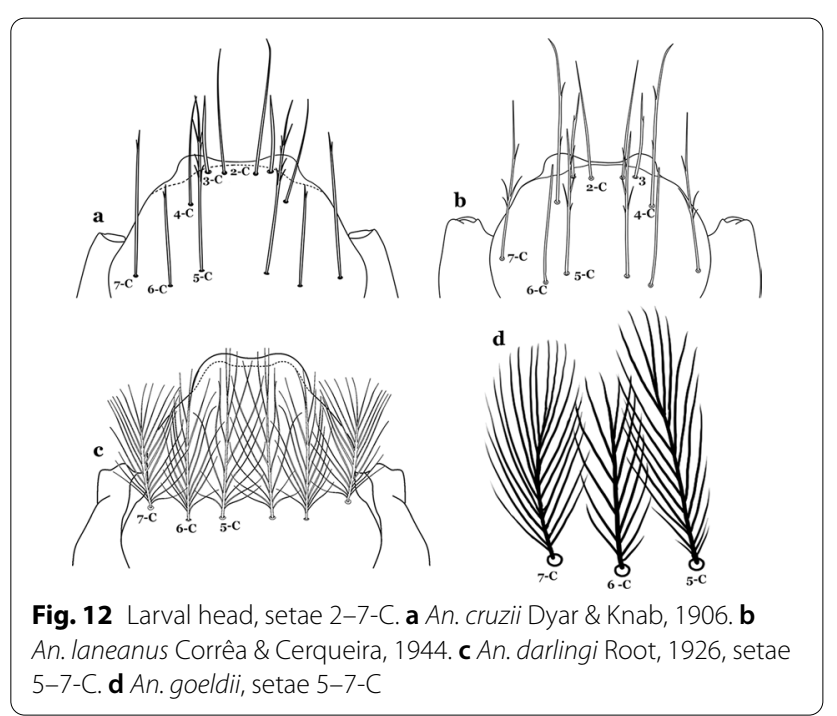

6a (5a) Seta 1-I single or branched, not palmate .7

6b Seta 1-I branched, palmate (Fig. 13a, b) .13 

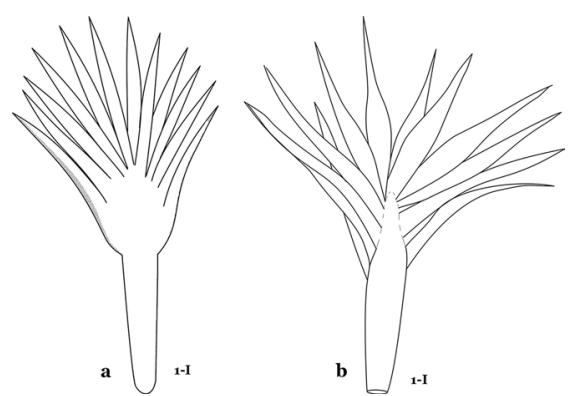

Fig. 13 Abdominal seta 1-I. a An. cruzii. b An. bellator

7a (6a) Setae 5,7-C branched apically; seta 6-C usually single (Fig. 14a).

..An. rollai

7b Setae 5,6-C usually single (Fig. 14b); seta 7-C single or double

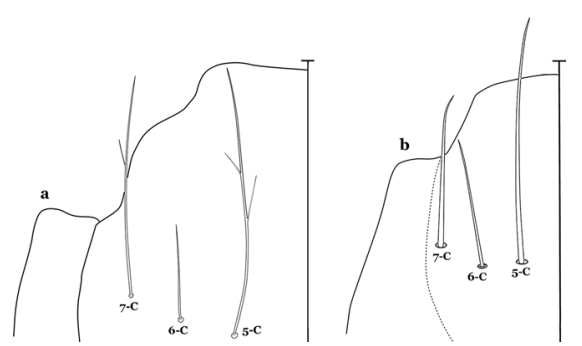

Fig. 14 Larval head, setae 5-7-C. a An. rollai Cova Garcia, Pulido F. \& Escalante de Ugueto, 1977. b An. boliviensis (Theobald, 1905)

8a (7b) Seta 9-II-VII single (Fig. 15a); seta 11-C single (Fig. 15b) ... An. gonzalezrinconesi

8b Seta 9-II,III branched, 9-IV-VII single or branched; seta 11-C single or with 2 or 3 apical branches (Fig. 15b, c) ...9

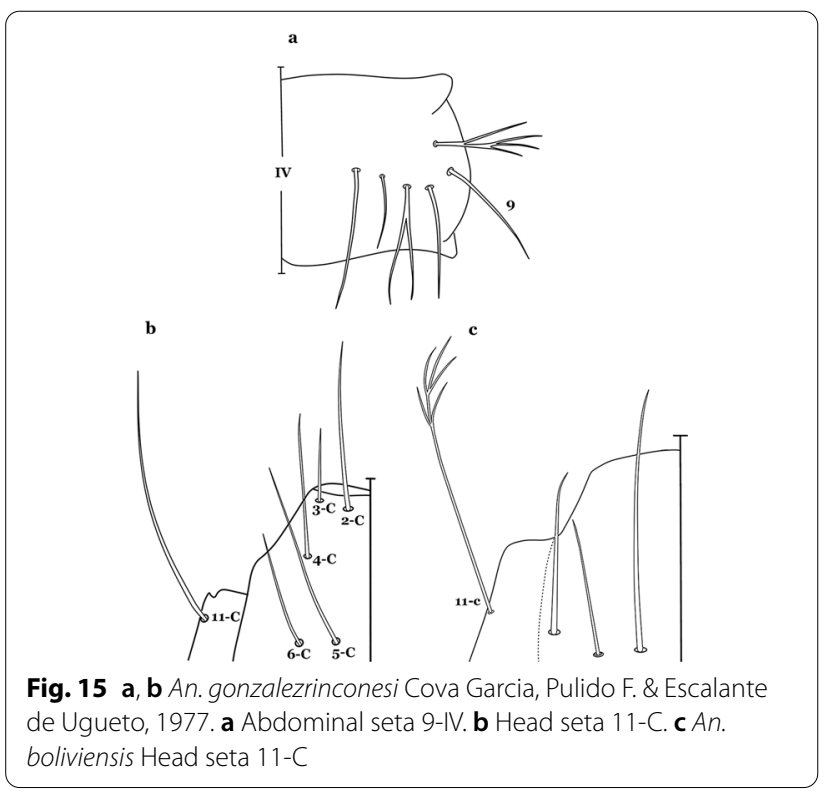

9a (8b) Seta 1-II-VI with sharply pointed leaflets An. boliviensis

9b Seta 1-II-VI fan-like, with blunt-tipped leaflets spreading outward so the seta resembles a fan, or truncate (Fig. 16).....

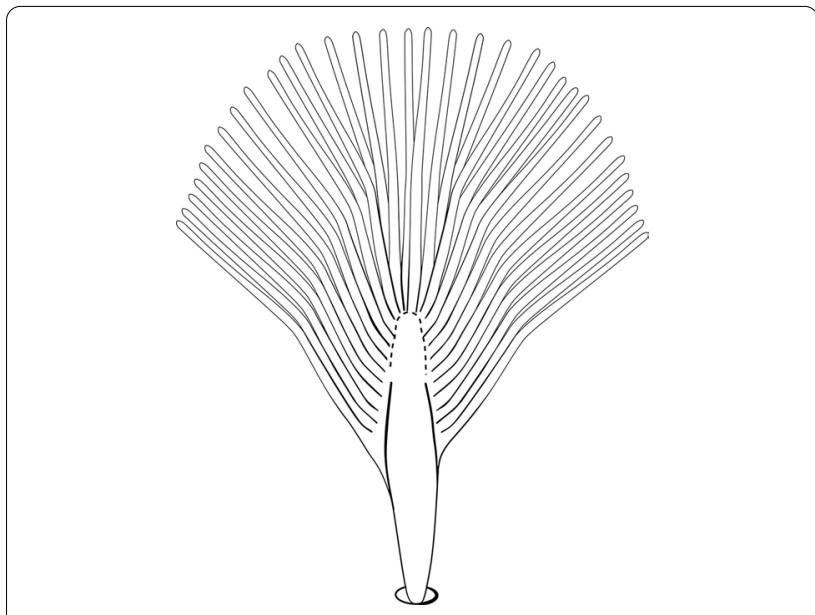

Fig. 16 Abdominal seta 1-II-VI. An. neivai Howard, Dyar \& Knab, 1913

10a (9b) Seta 1-VII fan-like plumose (Fig. 16); seta 6-VI long, aciculate, similar to 6-III-V (Fig. 17a).............11

10b Seta 1-VII not palmate (Fig. 17b); seta 6-VI moderately long to long, not simple, or with a few long proximal aciculae (Fig. 17c), different from 6-III-V, with filamentous branches. . .12

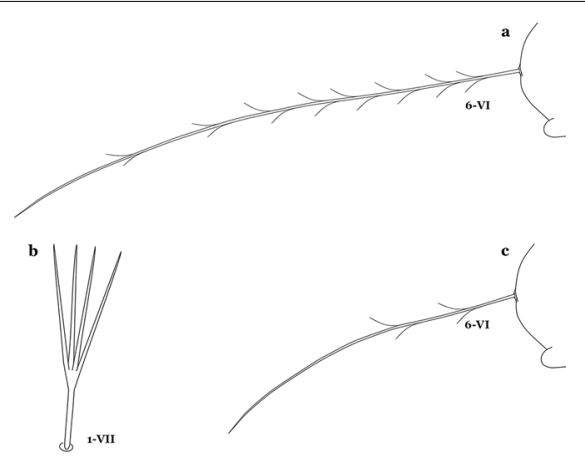

Fig. 17 a An. neivai abdominal seta 6-VI. An. pholidotus Zavortink, 1973. b Abdominal seta 1-VII. c Abdominal seta 6-VI

11a (10a) Seta 13-III-V usually triple and shorter than its corresponding abdominal segment (Fig. 18a) .......

An. neivai

11b Seta 13-III-V usually double and much longer than its corresponding abdominal segment (Fig. 18b) ........ An. auyantepuiensis 


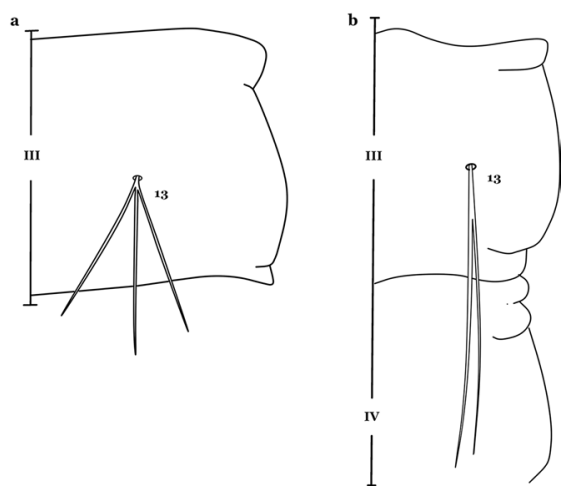

Fig. 18 Abdominal seta 13-III. a An. neivai. b An. auyantepuiensis Harbach \& Navarro, 1996

12a (10b) Seta 3-C stout, moderately long, greater than 0.5 length of 2-C (Fig. 19a); seta 11-P well developed, longer than 0.5 length of 9-P (Fig. 19b)

An. pholidotus

12b Seta 3-C short and stout, spiniform, shorter than 0.5 length of 2-C (Fig. 19c); seta 11-P less developed, shorter than 0.5 length of 9-P (Fig. 19d)

An. lepidotus

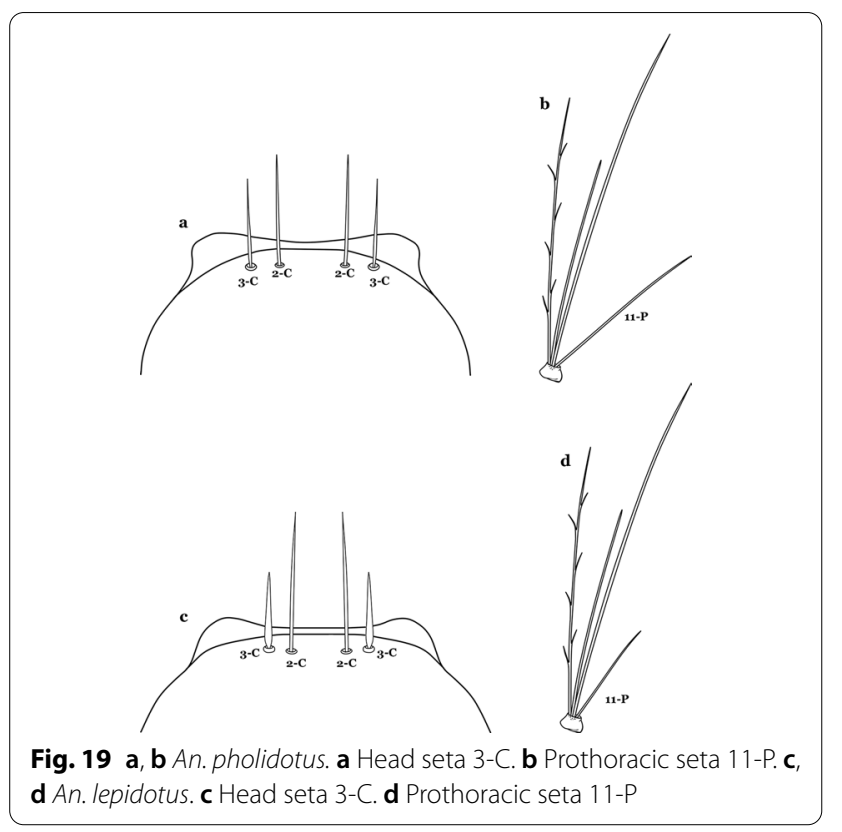

13a (6b) Seta 1-I with large lanceolate leaflets, similar to 1-II-VI (Fig. 20a); seta 6-VI with some long proximal aciculae (Fig. 20b) ..An. bambusicolus

13b Seta 1-I-VII with narrow pointed leaflets (Fig. 20c); seta 6-VI aciculate (Fig. 20d). . .14

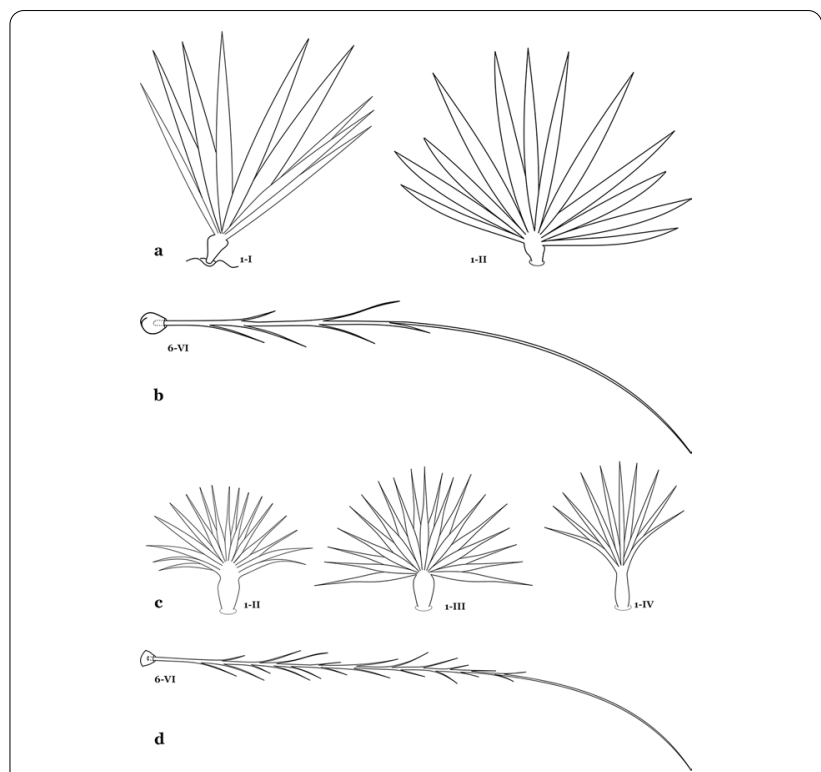

Fig. 20 a, b An. bambusicolus Komp, 1937. a Abdominal seta 1-I, II. b Abdominal seta 6-IV. c An. bellator, abdominal seta 1-II-IV. d An. cruzii, abdominal seta $6-\mathrm{Vl}$

14a (13b) Seta 1-S branched (Fig. 21a) .........An. bellator 14b Seta 1-S single (Fig. 21b) or weakly aciculate.

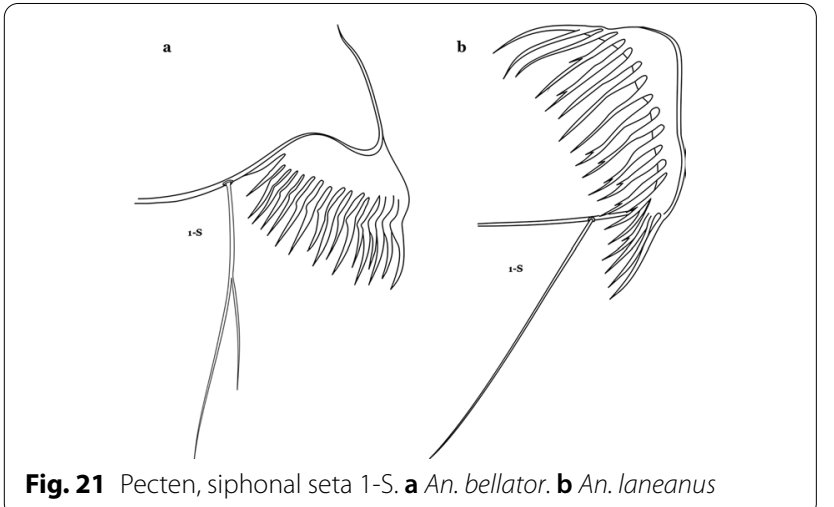

15a (14b) Saddle strongly sclerotized, dark brown (Fig. 22a); living larva pale purple, more evident in fourth instars... An. homunculus

15b Saddle lightly sclerotized, pale or light brown (Figs. 22b and 22c); living larva reddish, more evident in fourth instars. 


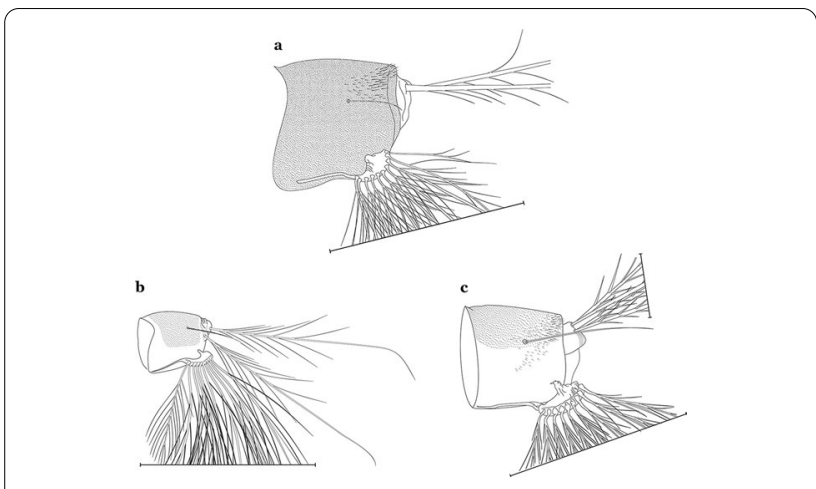

Fig. 22 Abdominal segment X. a An. homunculus Komp, 1937. b An. cruzii. c An. laneanus

16a (15b) Seta 8-C extends well past base of 6-C; seta 4-C much longer than seta 2-C; seta $2-\mathrm{C}$ with or without obvious aciculae (Fig. 23a.........An. laneanus

$16 \mathrm{~b}$ Seta 8-C not extending well past base of 6-C; seta 4-C shorter than seta $2-C$; setae $2-C$ or $3-C$, or both, single, seta 3-C simple or with a few aciculae (Fig. 23b) An. cruzii
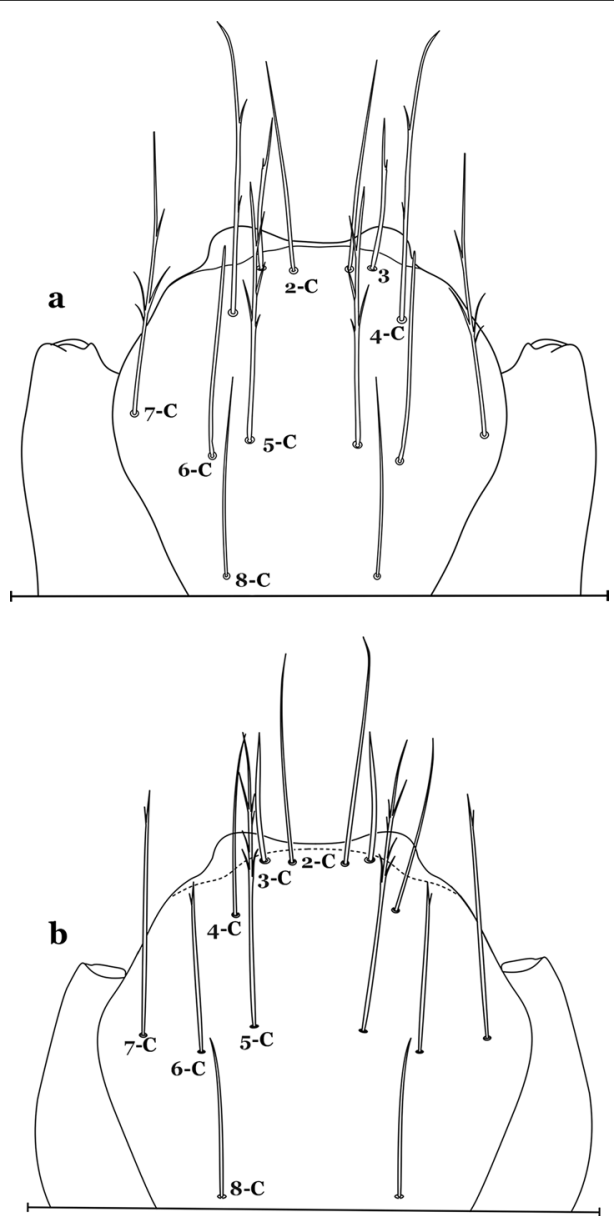

Fig. 23 Larva head, dorsal view, setae 2-8-C. a An. laneanus. b An. cruzii 17a (5b) Seta 6-IV,V single (Fig. 24a)

17b Setae 6-IV,V double or multi-branched (Fig. 24b, c)

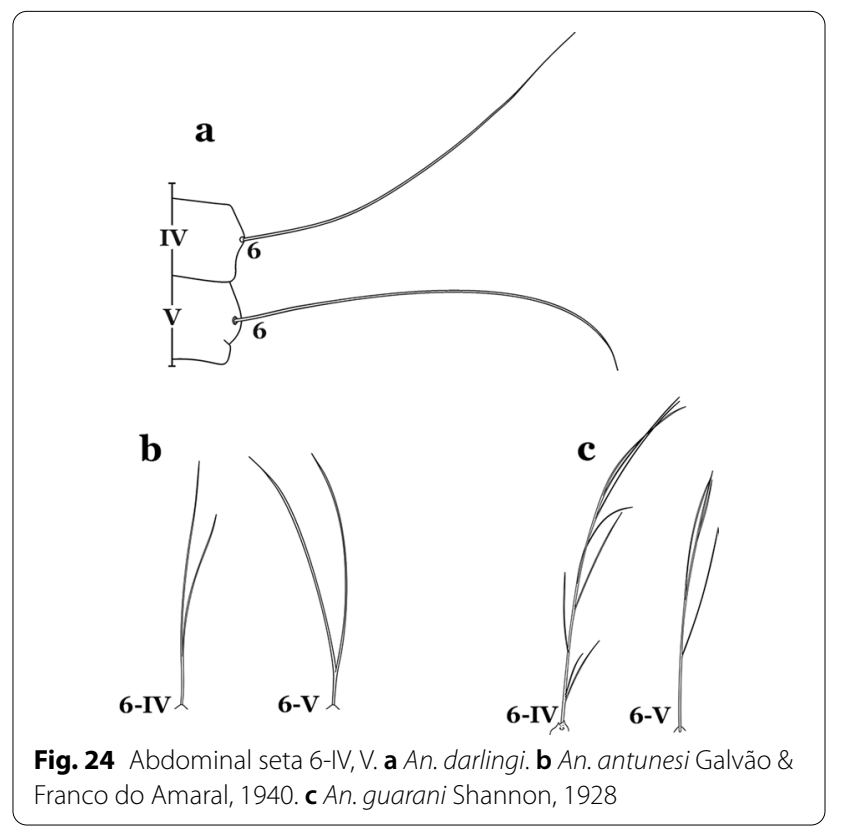

18a (17a) Seta 1-P plumose, with slender branches (Fig. 25a, b) 19

18b Seta 1-P fan-like, with thickened or lanceolate branches (Fig. 25c, d) .23

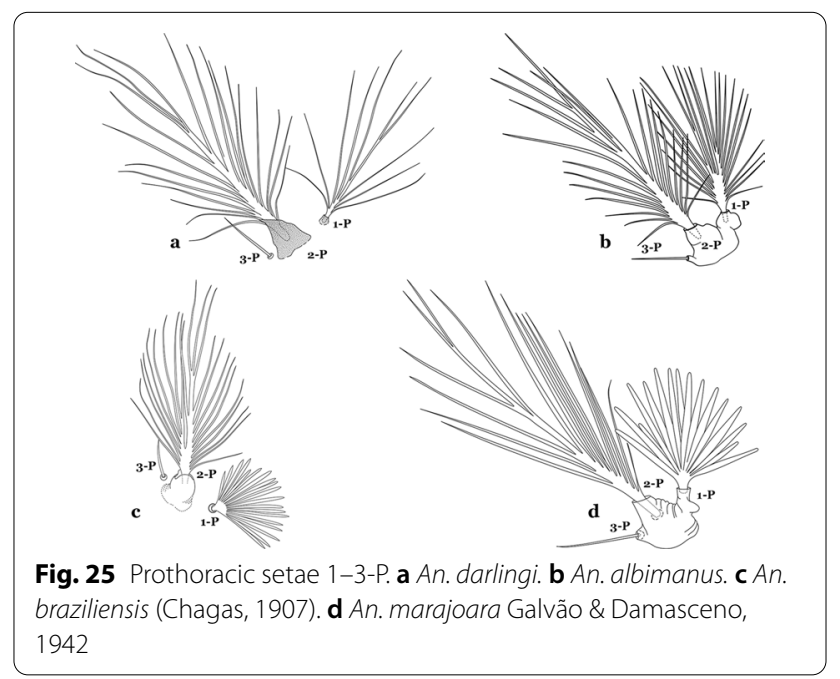

19a (18a) Seta 13-S well developed, long, approximately 2.2-2.5 length of saddle (Fig. 26a) An. darlingi 19b Seta 13-S much shorter than saddle (Fig. 26b) .....20 


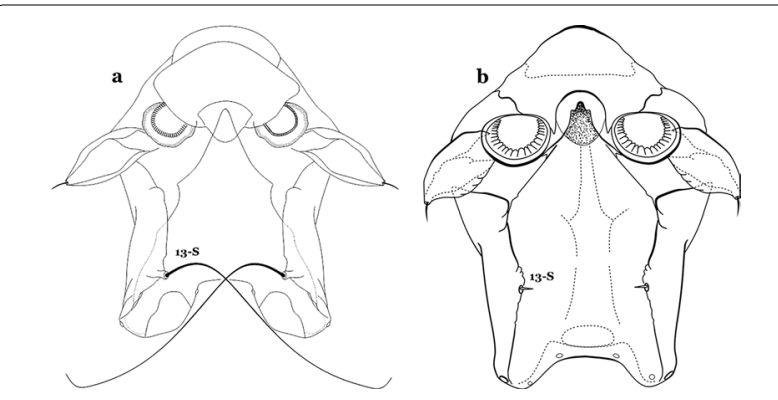

Fig. 26 Spiracular apparatus, seta 13-S. a An. darlingi. b An. albimanus

20a (19b) Seta 3-C multi-branched distally, with long branches (Fig. 27a); clypeal index 1.35-2 ......

An. lanei

20b Seta 3-C aciculate or with short branches (Fig. 27b); clypeal index variable .21

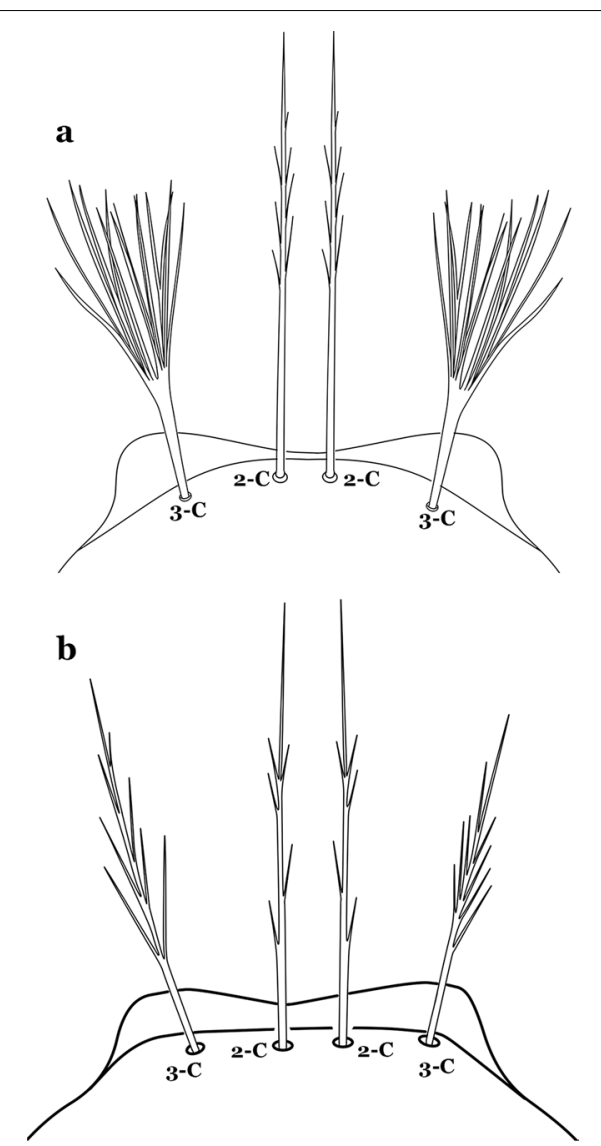

Fig. 27 Larva head, dorsal view, seta 3-C. a An. lanei Galvão \& Franco do Amaral, 1938. b An. albimanus

21a (20b) Setae 1-3-P inserted on a common tubercle (Fig. 28a); clypeal index about 1.25 ......An. albimanus 21b Setae 1-3-P inserted on separate tubercles (Fig. 28b); clypeal index greater than 4.0 .22

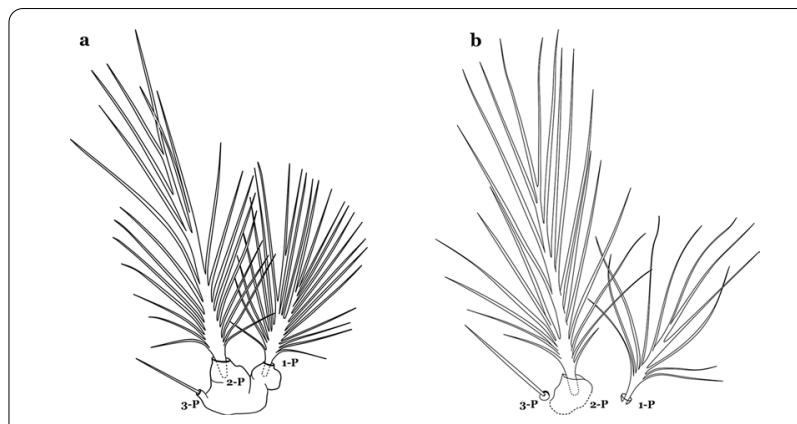

Fig. 28 Prothoracic setae 1-3-P. a An. albimanus. b An. argyritarsis Robineau-Desvoidy, 1827

22a (21b) Seta 3-T fan-like, with long narrow filamentous branches (Fig. 29a); seta 1-I pectinate with narrow, poorly sclerotized leaflets (Fig. 29b)...

.An. sawyeri

22b Seta 3-T not fan-like, more or less pectinate, with filamentous branches (Fig. 29c); seta 1-I fan-like, with filamentous, poorly sclerotized branches (Fig. 29d) An. argyritarsis

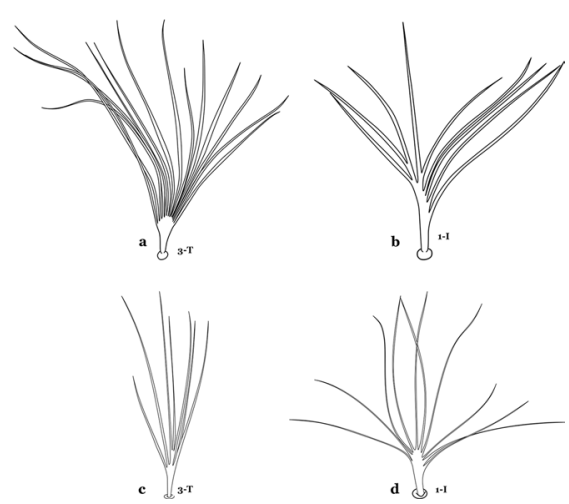

Fig. 29 a, b An. sawyeri Causey, Deane, Deane \& Sampaio, 1943 a Prothoracic seta 3-T. b Abdominal seta 1-I. c, d An. argyritarsis. c Prothoracic seta 3-T. d Abdominal seta 1-1

23a (18b) Seta 2-C moderately separated, closer together than distance between $2-\mathrm{C}$ and $3-\mathrm{C}$, clypeal index usually 2.5 or more (Fig. 30a).............24

23b Seta 2-C well separated, distance between them about equal to distance between $2-\mathrm{C}$ and $3-\mathrm{C}$, clypeal index less than 2.5 (Fig. 30b) .25 


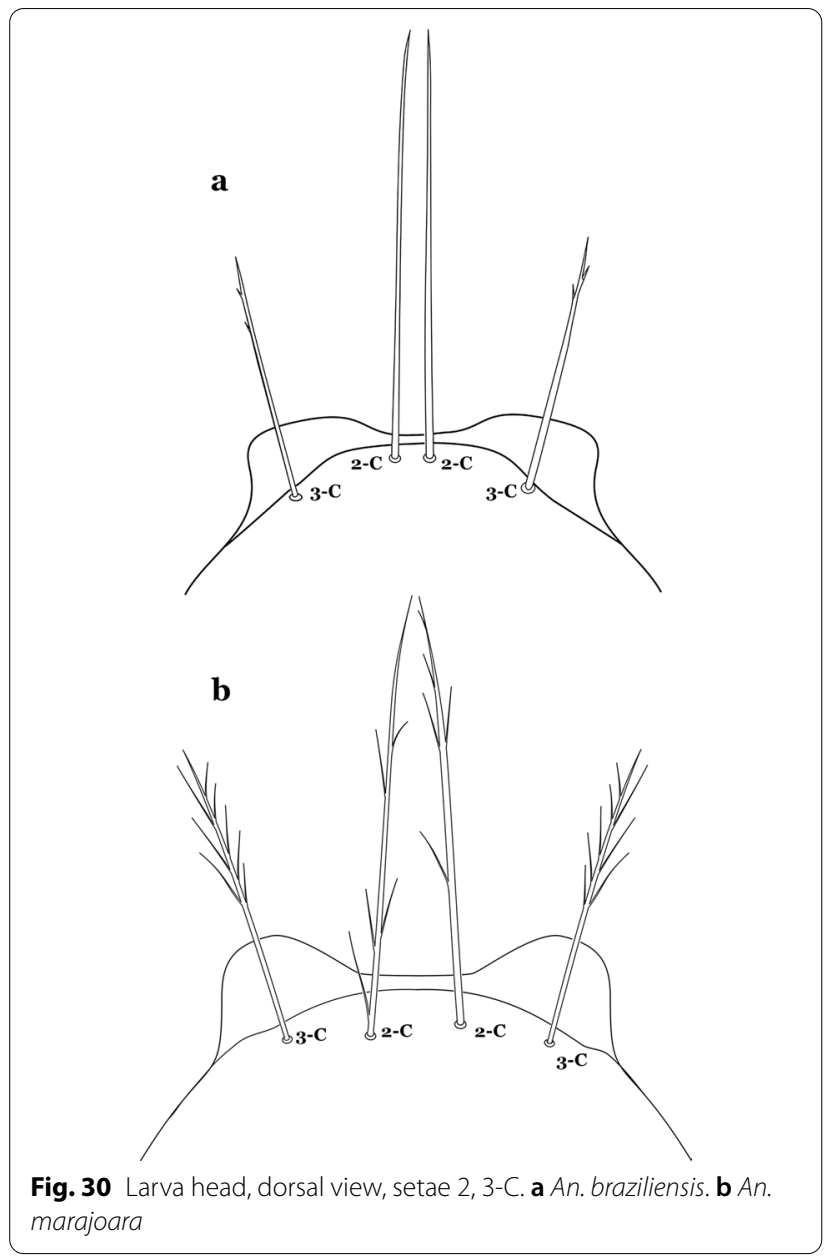

24a (23a) Seta 1-P with moderately broad blunt-topped branches tips (Fig. 31a); seta 4-C long, single or double (Fig. 31b); setae 1,2-P usually inserted on a common tubercle (Fig. 31a)..................An. braziliensis

24b Seta 1-P with narrow acuminate branches (Fig. 31c); seta 4-C short, with 1-4 branches (Fig. 31d); setae 1,2-P not inserted on a common tubercle (Fig. 31c). An. strodei \& An. rondoni

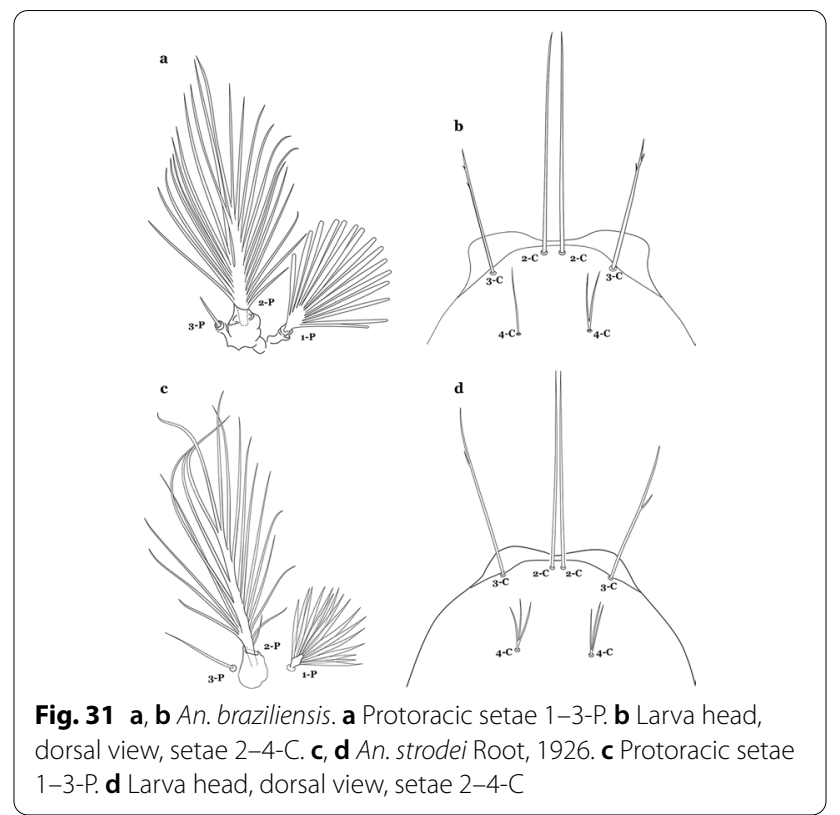

25a (23b) Seta 1-3-P usually inserted on common tubercle (Fig. 32a) or seta 1-P separate, inserted on a sclerotized tubercle of variable development...........26

25b Setae 1-3-P inserted on separate tubercles (Fig. 32b) .27

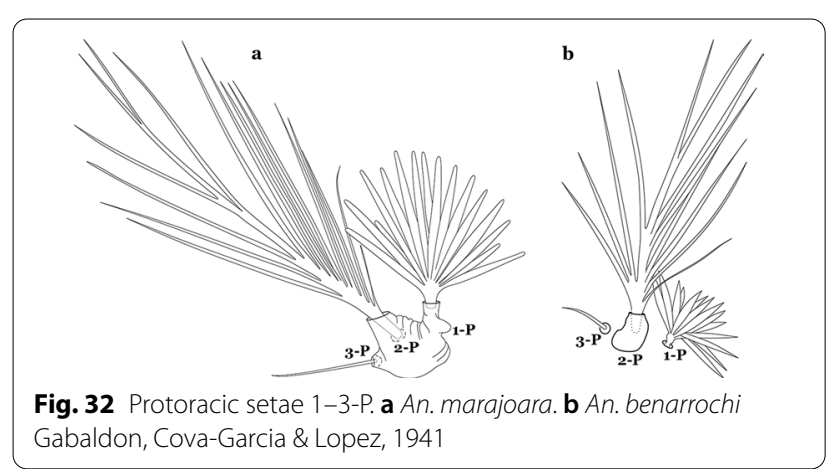

26a (25a) Seta 3-C with short aciculae (Fig. 33a)..... An. albitarsis, An. janconnae, An. marajoara \& An. oryzalimnetes

26b Seta 3-C branched distally (Fig. 33b)

An. deaneorum 


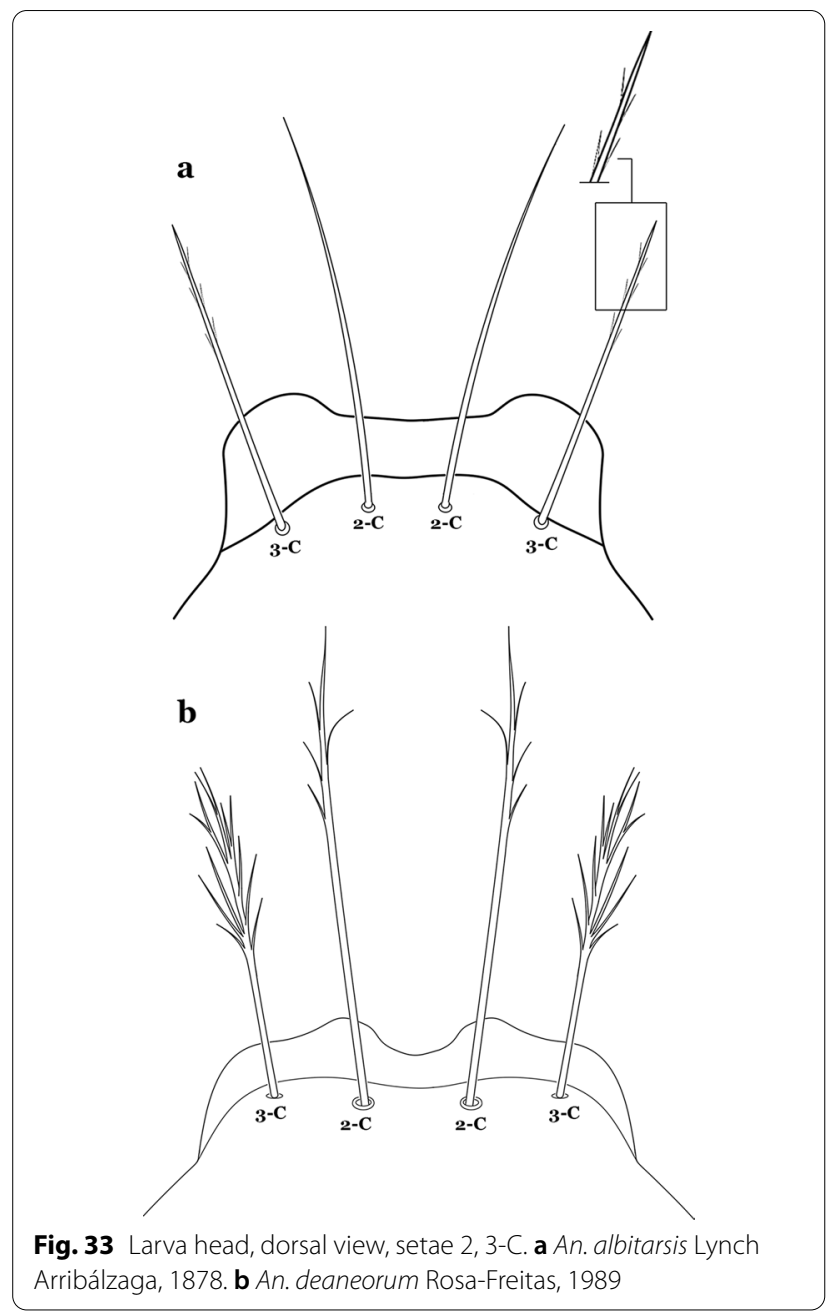

27a (25b) Setae 2,3-C branched (Fig. 34a) ..28 27b Setae 2,3-C simple (Fig. 34b) or aciculate, sometimes apically branched ...30

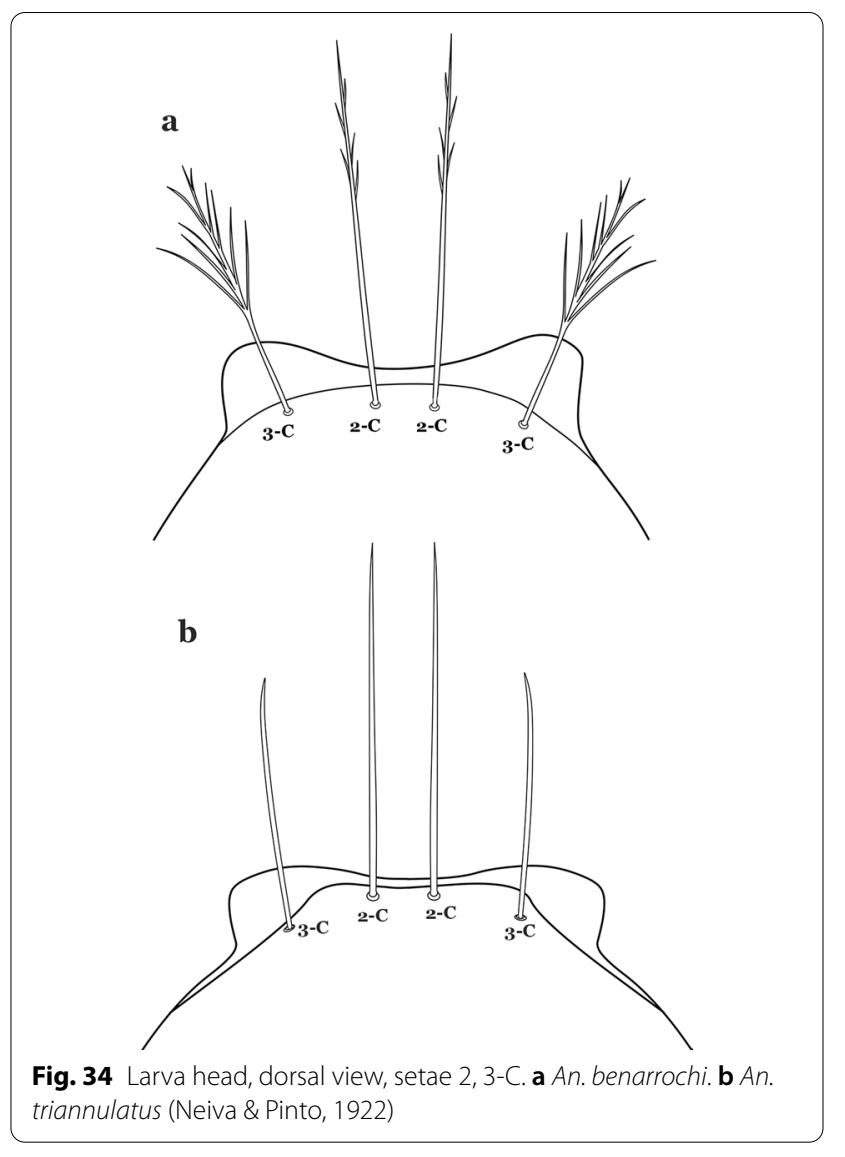

28a (27a) Seta 1-A at least 2 times longer than width of antenna at point of insertion (Fig. 35a); seta 1-X as long or slightly longer than saddle (Fig. 35b); seta 3-C branches longer than those of seta 2-C (Fig. 34a)... An. benarrochi

$28 \mathrm{~b}$ Seta 1-A less than twice as long as width of antenna at point of insertion (Fig. 35c), sometimes minute; seta 1-X shorter than saddle; setae 2,3-C branches similar in size or 3-C branches slightly longer than 2-C branches (Fig. 35d). . .29 


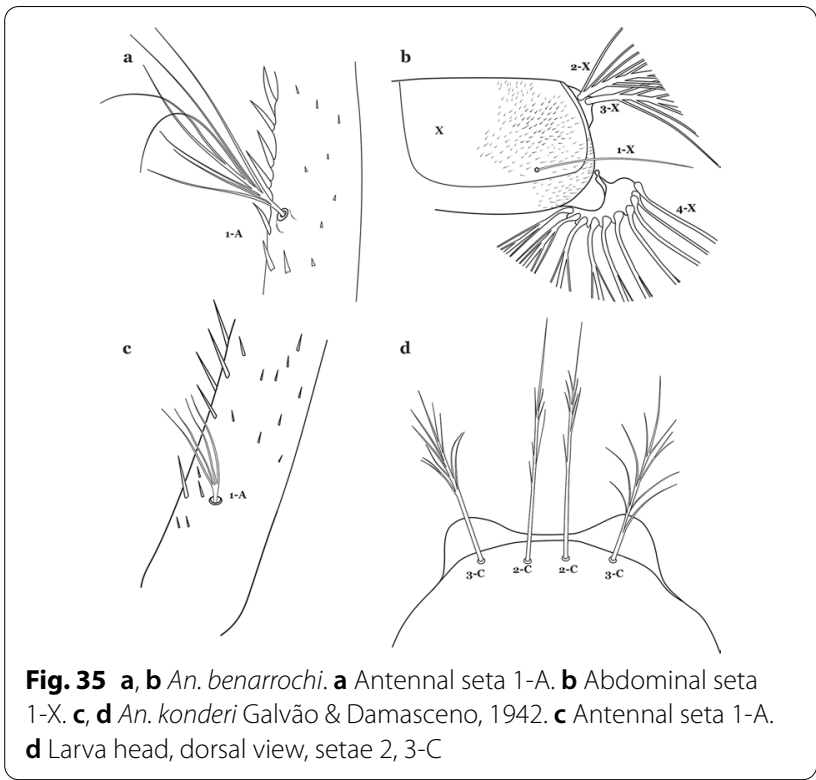

29a (28b) Setae 2,3-C with simple branches, rarely dendritic, branches begin on distal half (Fig. 36a); seta 1-X inserted on saddle (Fig. 36b) or in an indentation at or near ventral margin; lateral arms of median plate of spiracular apparatus minute (Fig. 36c); anal papillae usually short, approximately 0.5 length of segment $\mathrm{X}$ (Fig. 36b) ........An. aquasalis

$29 \mathrm{~b}$ Setae 2,3-C branched, branches begin on proximal half (Fig. 36d); seta 1-X not inserted on saddle (Fig. 36e); lateral arms of median plate of spiracular apparatus moderately long (Fig. 36f); anal gills long, as long or longer than saddle (Fig. 36e)

An. oswaldoi \& An. konderi

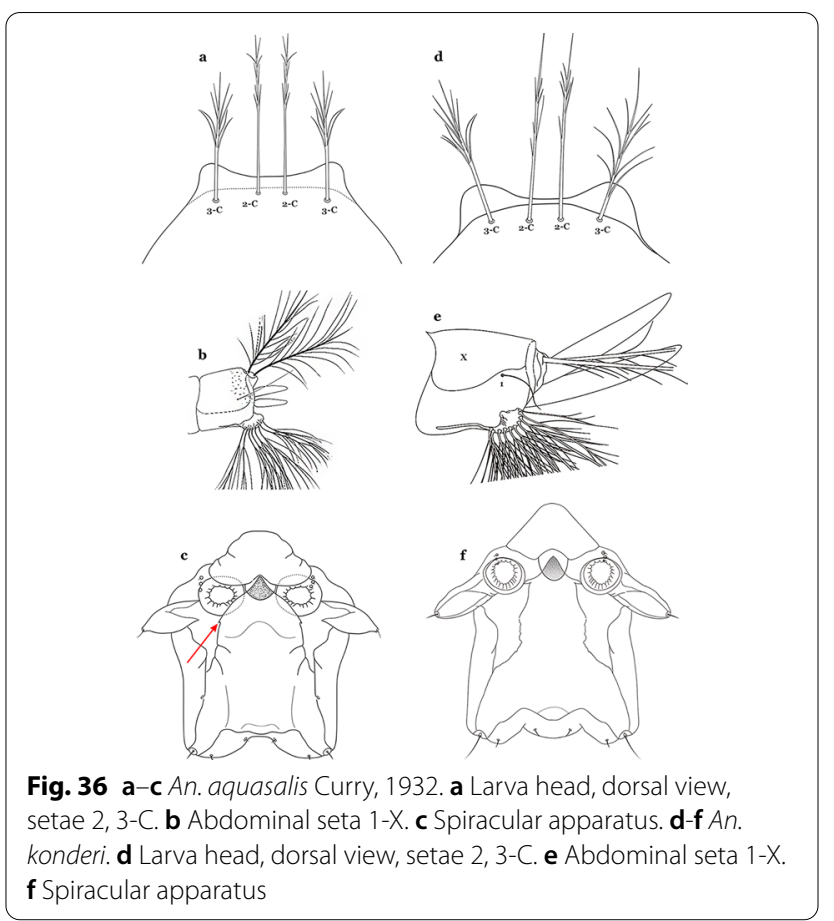

30a (27b) Lateral arm of median plate of spiracular apparatus long or moderately long, projecting laterally (Fig. 37a)

.31

30b Lateral arm of median plate of spiracular apparatus absent or small, projecting caudolaterally when present (Fig. 37b).

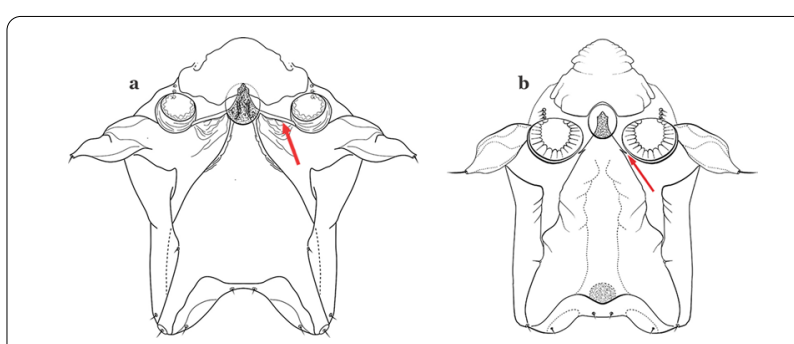

Fig. 37 Spiracular apparatus. a An. triannulatus. b An. nuneztovari Gabaldon, 1940

31a (30a) Seta 11-I long, with 2-4 stiff branches; seta 13-I short to moderately long, usually with 4-9 branches (Fig. 38a); seta 1-P with moderately broad lanceolate branches (Fig. 38b); lateral arm of median plate of spiracular apparatus truncate at apex, stout and relatively short (Fig. 38c) An. ininii

31b Seta 11-I long, with 3-7 branches; seta 13-I long, with 2-4 branches (Fig. 38d); seta 1-P with broad or narrow lanceolate leaflets (Fig. 38e); lateral arm of median plate of spiracular apparatus truncate at apex, slender and moderately long to long (Fig. 38f) 

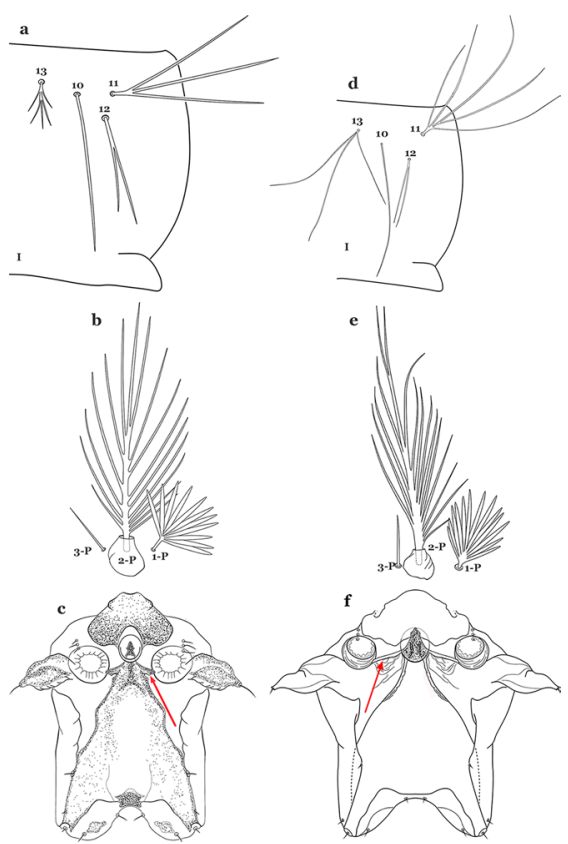

Fig. 38 a-c An. ininii Senevet \& Abonnenc, 1938. a Abdominal setae 11-13-I. b Prothoracic setae 1-3-P. c Spiracular apparatus. d-f $A n$. triannulatus. d Abdominal setae 11-13-I. e Prothoracic setae 1-3-P. f Spiracular apparatus

32a (31b) Seta 1-P with narrow lanceolate branches (Fig. 39a); lateral arm of median plate of spiracular apparatus long and slender (Fig. 39b)

An. triannulatus

32b Seta 1-P with narrow acuminate branches (Fig. 39c); lateral arm of median plate of spiracular apparatus shorter and stouter (Fig. 39d).

An. halophylus
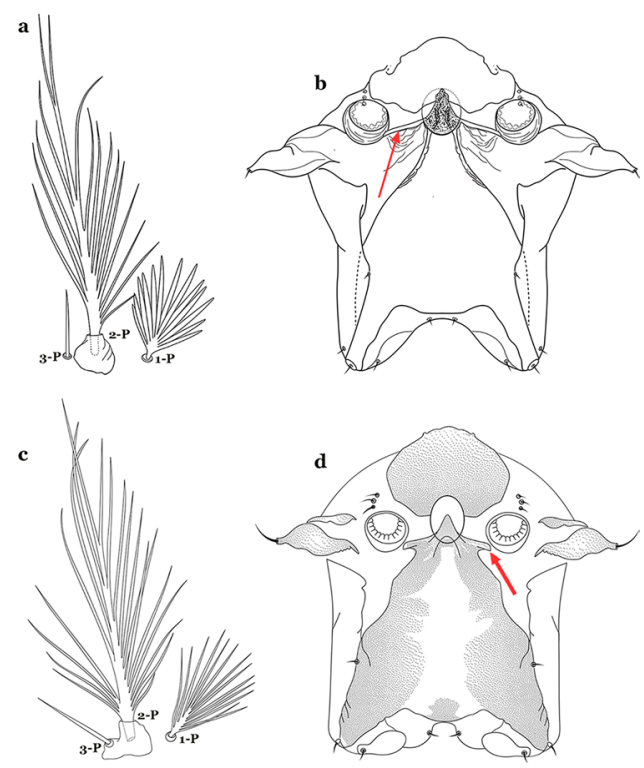

Fig. 39 a, b An. triannulatus. a Prothoracic setae 1-3-P. b

Spiracular apparatus. c, d An. halophylus Silva do Nascimento \& Lourenço-de-Oliveira, 2002. c Prothoracic setae 1-3-P. d Spiracular apparatus

33a (30b) Seta 11-I moderately long, with 3-7 branches; seta 13-I long, with 2-4 branches (Fig. 40a); seta 1-P with narrow acuminate branches (Fig. 40b) An. halophylus

33b Seta 11-I very long, with 2-4 branches; seta 13-I small, usually with more than 3 branches (Fig. 40c); seta 1-P with narrow to broad lanceolate branches (Fig. 40d)
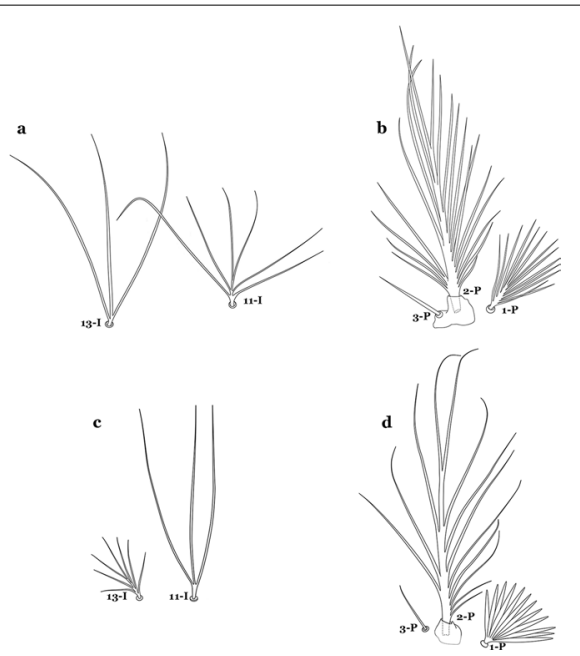

Fig. 40 a, b An. halophylus. a Abdominal setae 11,13-I. b Prothoracic setae 1-3-P. c, d An. nuneztovari. c Abdominal setae 11,13-I. d Prothoracic setae 1-3-P 
34a (33b) Seta 4-C single or double, moderately long, usually extending beyond base of 2-C (Fig. 41a) ....35

34b Seta 4-C short, branched from base, usually not extending as far as base of 2-C (Fig. 41b). . .36

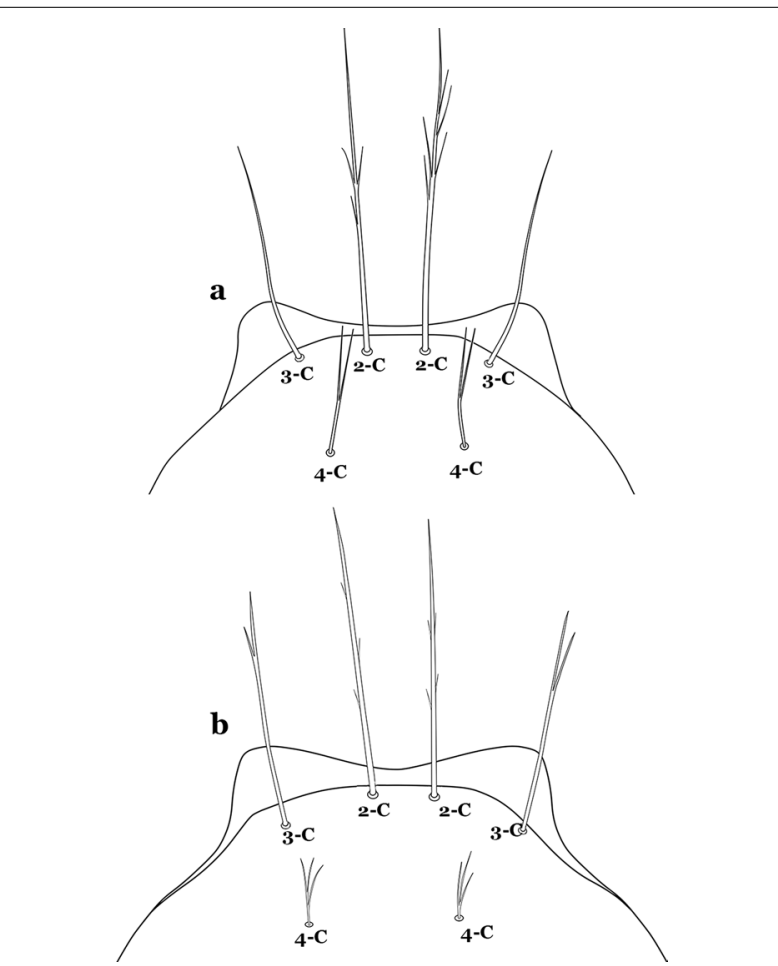

Fig. 41 Larva head, dorsal view, setae 2-4-C. a An. nuneztovari. b An. rangeli Gabaldon, Cova-Garcia \& Lopez, 1940

35a (34a) Seta 0-II short, approximately 0.5 or less length of leaflets of seta 1-II, 1-3-branched (Fig. 42a); seta 4-C 0.7 length of 3-C (Fig. 42b) An. dunhami \& An. trinkae

$35 \mathrm{~b}$ Seta 0-II subequal or longer than length of leaflets of 1-II, 5-8-branched (Fig. 42c); seta 4-C 0.3-0.6 length of 3-C (Fig. 42d)

An. goeldii \& An. nuneztovari

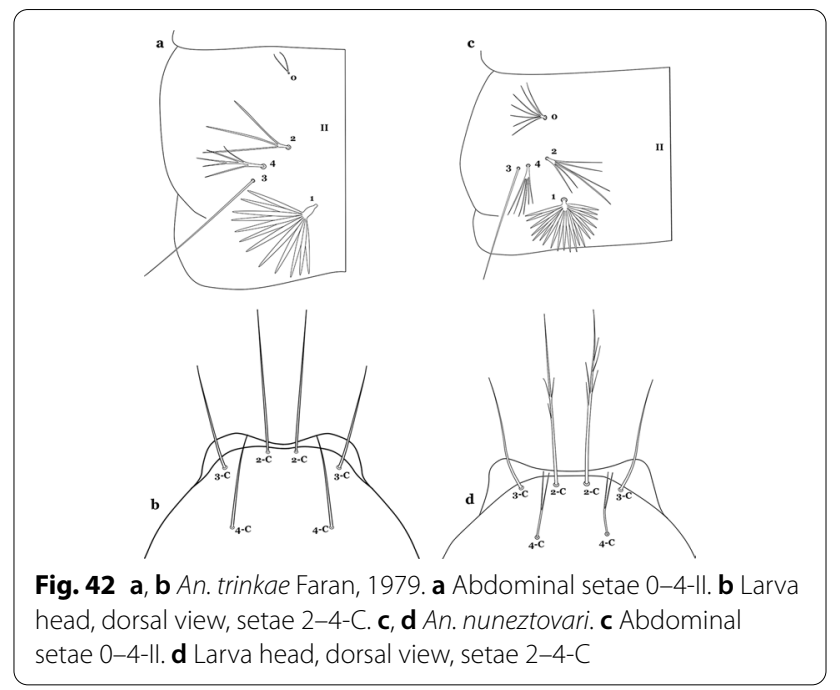

36a (34b) Setae 2,3-C aciculate, with short, fine branches (Fig. 43a). An. rangeli

36b Setae 2,3-C with short thick aciculae (Fig. 43b), or long fine branches .37

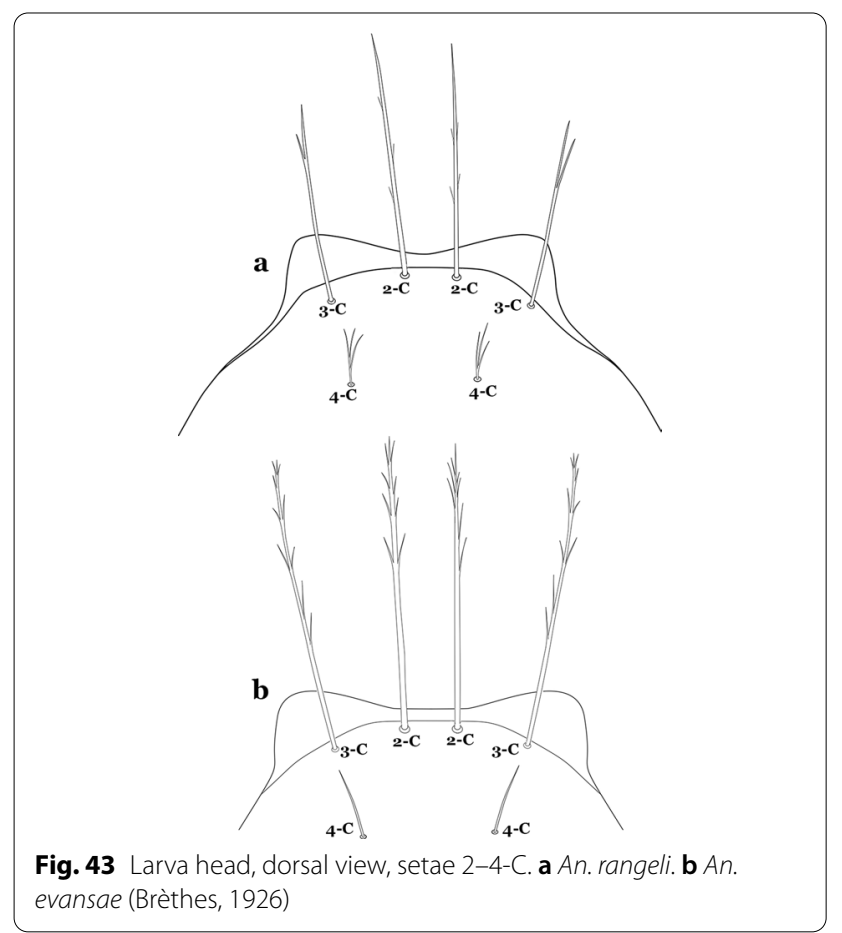


37a (36b) Seta 1-P with short, moderately broad branches, never narrow (Fig. 44a); lateral arm of median plate of spiracular apparatus small, or more strongly developed and discernable from median plate (Fig. 44b); seta 1-X inserted on (Fig. 44c) or outside saddle

An.galvaoi

37b Seta 1-P with long narrow branches (Fig. 44d); lateral arm of median plate of spiracular apparatus minute (Fig. 44e); seta 1-X inserted on saddle (Fig. 44f) An. evansae

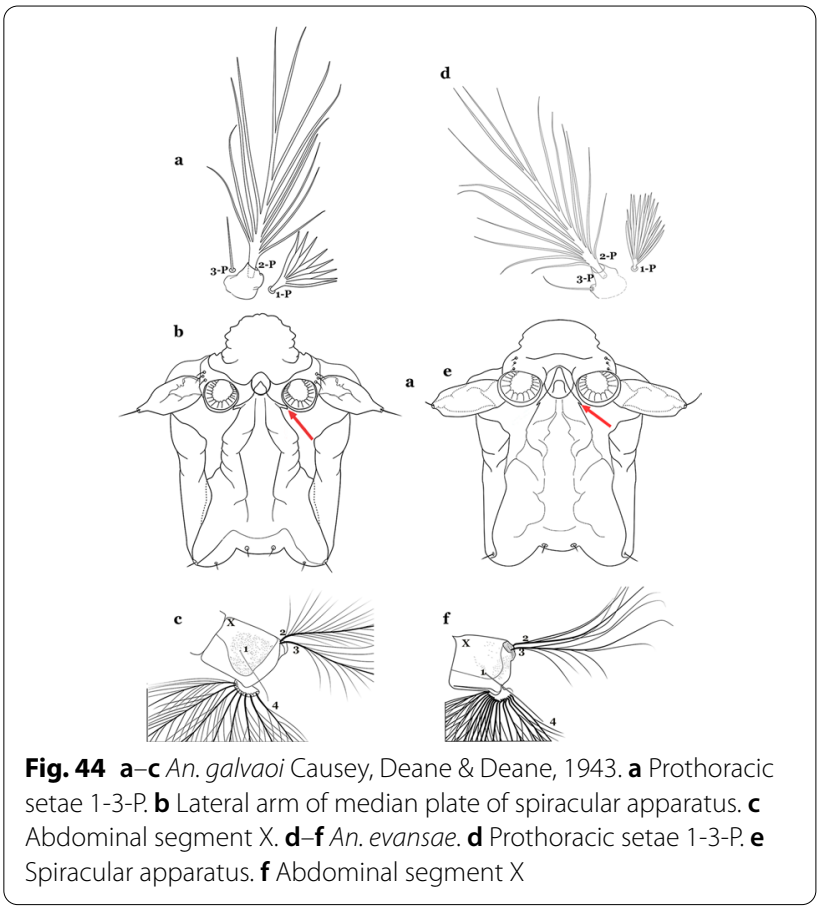

38a (17b) Seta 6-IV-VI double (Fig. 45a). .39 38b Seta 6-IV-VI multi-branched (Fig. 45b)

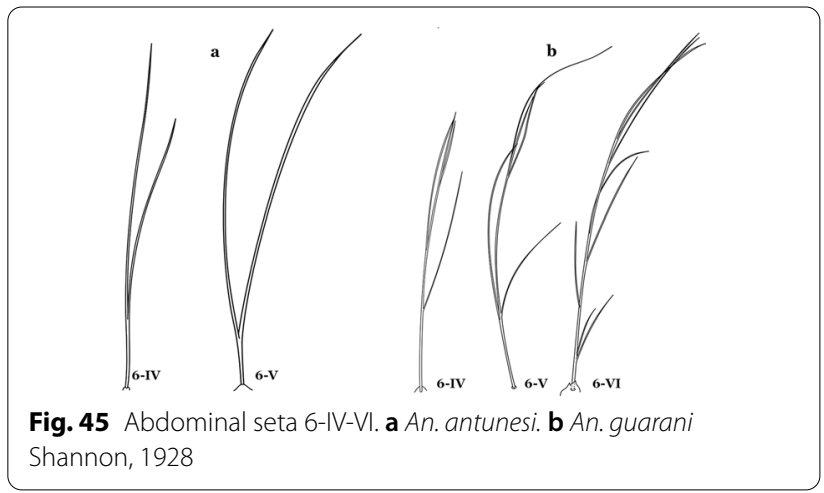

39a (38a) Seta 14-P long, extending beyond collar when specimen is mounted on a microscope slide (Fig. 46a); seta 4-C strongly developed, aciculate, extending to base of 2-C (Fig. 46b); seta 8-C branched (Fig. 46c)

An. antunesi

39b Seta 14-P moderately short, never reaching posterior end of head (Fig. 46d); seta 4-C double, not extending as far as base of 2-C (Fig. 46e); seta 8-C double (Fig. 46f) An. lutzii
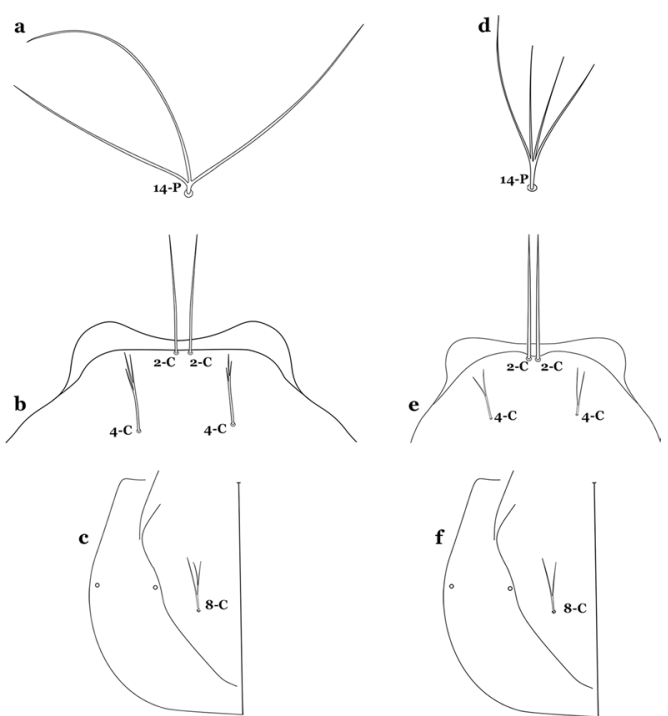

Fig. 46 a-c An. antunesi. a Prothoracic seta 14-P. b Larva head, dorsal view, setae 2,4-C. c Seta 8-C. d-f An. lutzii Cruz, 1901. d Prothoracic seta 14-P. e Larva head, dorsal view, setae 2,4-C. f Seta 8-C

40a (38b) Spiracular openings narrow, median plate with a heavily sclerotized mesal area, dark brown, paler laterally to posterior edge of plate (Fig. 47a) An. guarani

40b Spiracular openings large, median plate with a heavily sclerotized mesal area, or not uniformly sclerotized to posterior edge of plate (Fig. 47b)......41

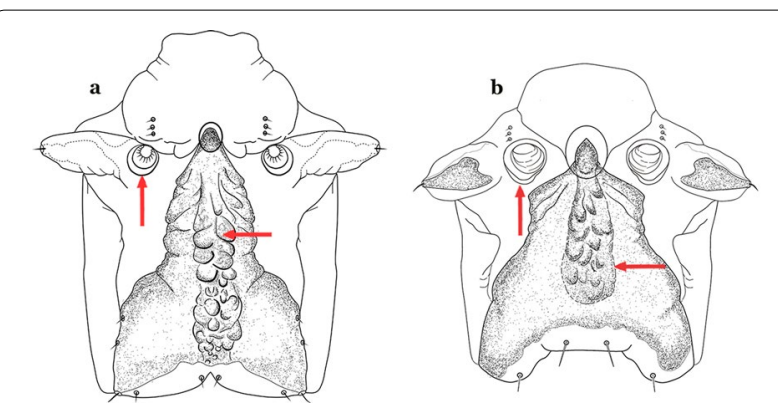

Fig. 47 Spiracular apparatus. a An. guarani. b An. parvus (Chagas, 1907) 
41a (40b) Median plate of spiracular apparatus with a heavily sclerotized mesal area (Fig. 48a); seta 1-IIVII well developed, with a short broad main stem (Fig. 48b); seta 1-A length less than twice width of antenna at point of insertion (Fig. 48c).........An. parvus

41b Median plate of spiracular apparatus with a strongly sclerotized mesal area posteriorly (Fig. 48d); seta 1-II-VII hyaline with a narrow long main stem (Fig. 48e); seta 1-A length more than twice width of antenna at point of insertion (Fig. 48f) An. pristinus

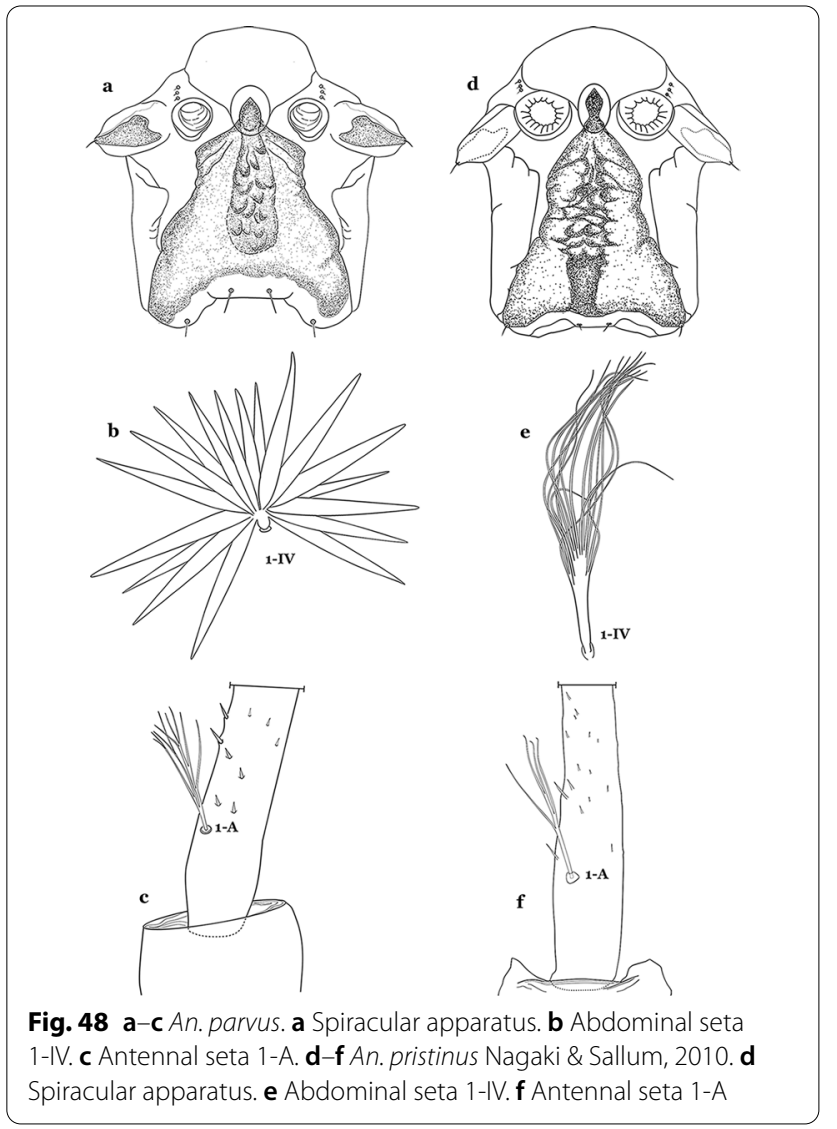

42a (4b) Posterolateral lobe of spiracular apparatus with a long caudal spine (Fig. 49a)

.An. pseudopunctipennis

42b Posterolateral lobe of spiracular apparatus without a long caudal spine (Fig. 49b) . .43

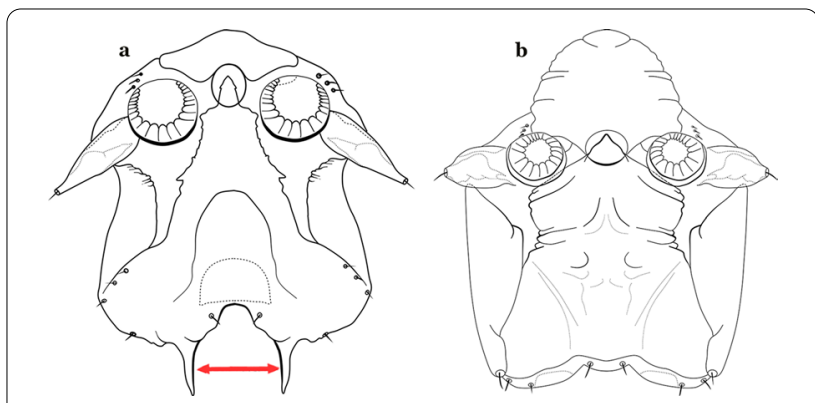

Fig. 49 Spiracular apparatus. a An. pseudopunctipennis. b An. pictipennis (Philippi, 1865)

43a (42b) Leaflets of seta 1-II-VII indistinctly serrate (Fig. 50a)... 44

43b Leaflets of seta 1-II-VII distinctly notched or serrate (Fig. 50b) .46
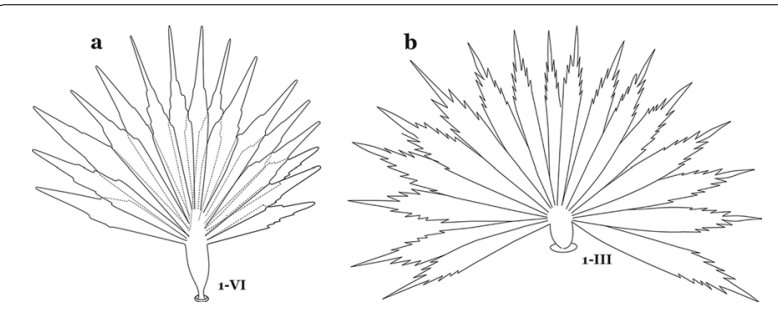

Fig. 50 Larval abdominal seta 1. a An. atacamensis González \& Sallum, 2010. b An. mattogrossensis

44a (43a) Seta 4-C long, reaching beyond anterior margin of head, nearly as long or as long as $2-\mathrm{C}$ or $3-\mathrm{C}$; setae 2-C well separated, as close to each other as each is to 3-C; clypeal index about 1.0 (Fig. 51a) ....45

44b Seta 4-C short to moderately long, not reaching beyond anterior margin of head, or not subequal to $2-\mathrm{C}$ or $3-\mathrm{C}$; setae $2-\mathrm{C}$ very close together, closer to another than either each is to $3-C$; clypeal index greater than 1.5 (Fig. 51b)

An. gomezdelatorrei \& An. oiketorakras 


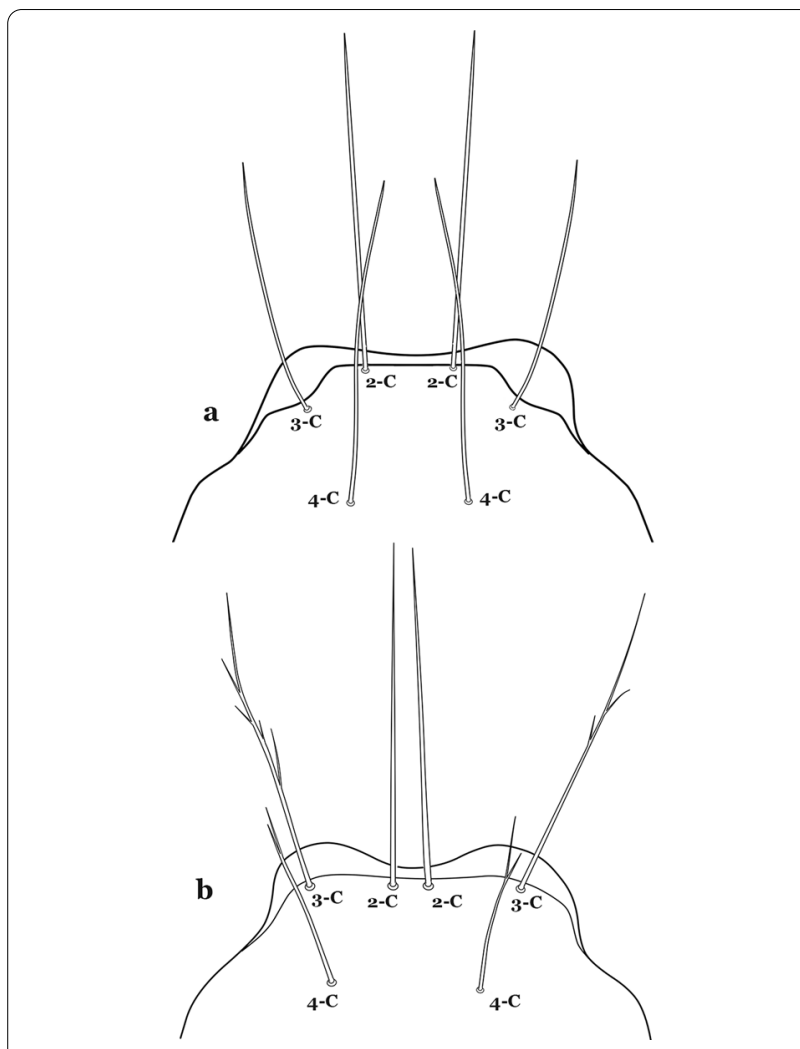

Fig. 51 Larva head, dorsal view, setae 2-4-C. a An. atacamensis. b An. oiketorakras Osorno-Mesa, 1947

45a (44a) Insertion of seta 7-C in line (transverse sense) with point of insertion of setae 5-C and 6-C; seta 5- $C$ extends to or beyond bases of $2-C$ or $3-C$ (Fig. 52a); seta 3-P inserted on same tubercle as 2-P (Fig. 52b) An. atacamensis

$45 \mathrm{~b}$ Insertion of seta 7-C anterior of line (transverse sense) of points of insertion of setae $5-C$ and $6-C$; seta 5-C extends to or nearly to bases of $2-\mathrm{C}$ or $3-\mathrm{C}$ (Fig. 52c); seta 3-P not inserted on a tubercle with 2-P (Fig. 52d) An. pictipennis

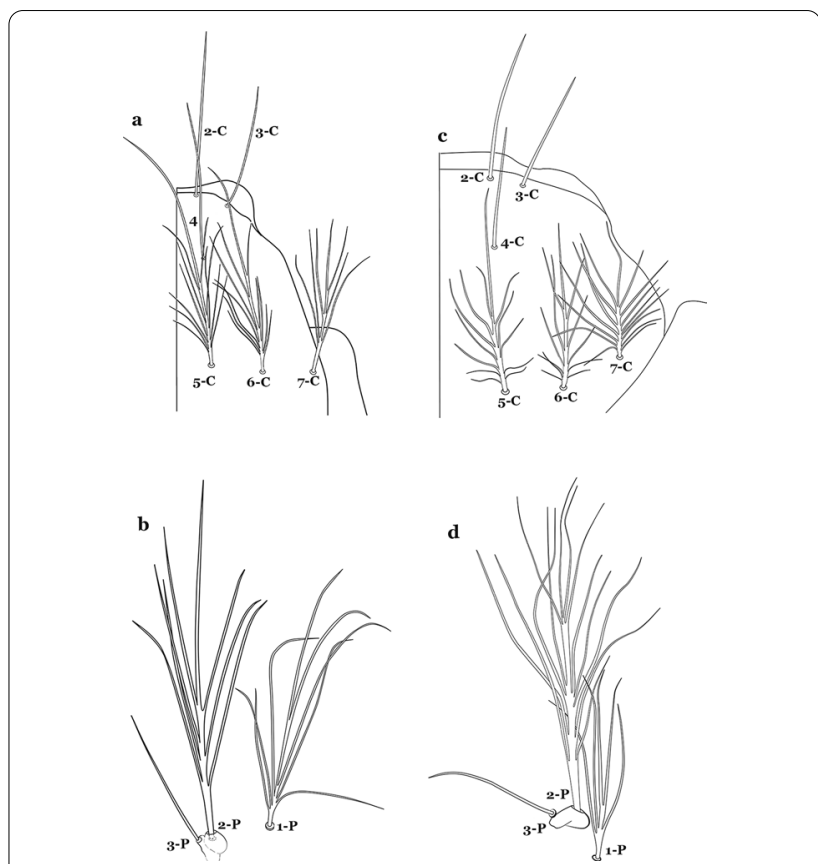

Fig. 52 a, b An. atacamensis. a Larva head, dorsal view, setae 2-7-C. b Prothoracic setae 1-3-P. c, d An. pictipennis. c Larva head, dorsal view, setae 2-7-C. d Prothoracic setae 1-3-P

46a (43b) Setae 2,3-A sharply pointed (Fig. 53a)..........47 $46 \mathrm{~b}$ Setae 2-A or 3-A truncate, other sharply pointed (Fig. 53b) . .55

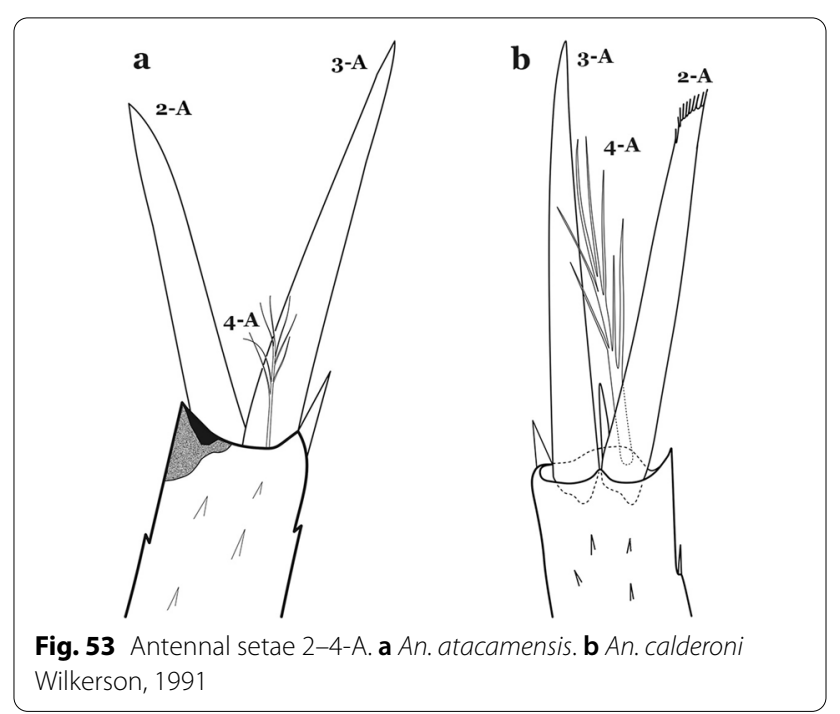


47a (46a) Seta 9-P single or double (Fig. 54a) . .48 47b Seta 9-P branched (Fig. 54b)

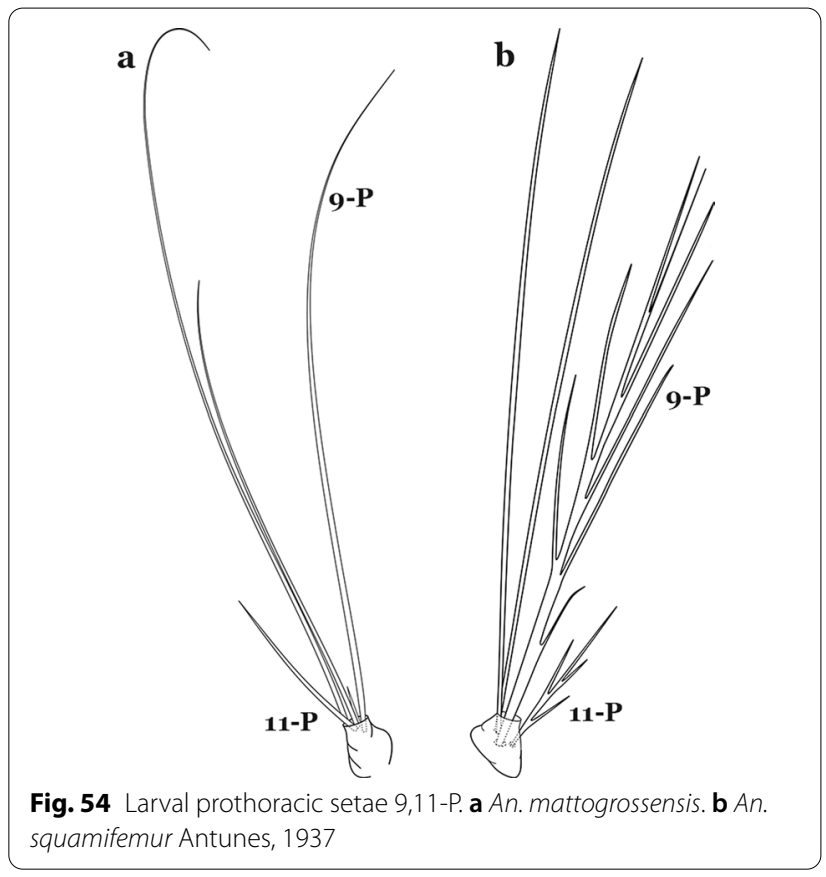

48a (47a) Ventral surface of thorax and abdomen spiculose An. minor

48b Ventral surface of thorax and abdomen smooth..49

49a (48b) Seta 3-C with 3 or more branches or dendritic (Fig. 55a)

49b Seta 3-C single or double (Fig. 55b)

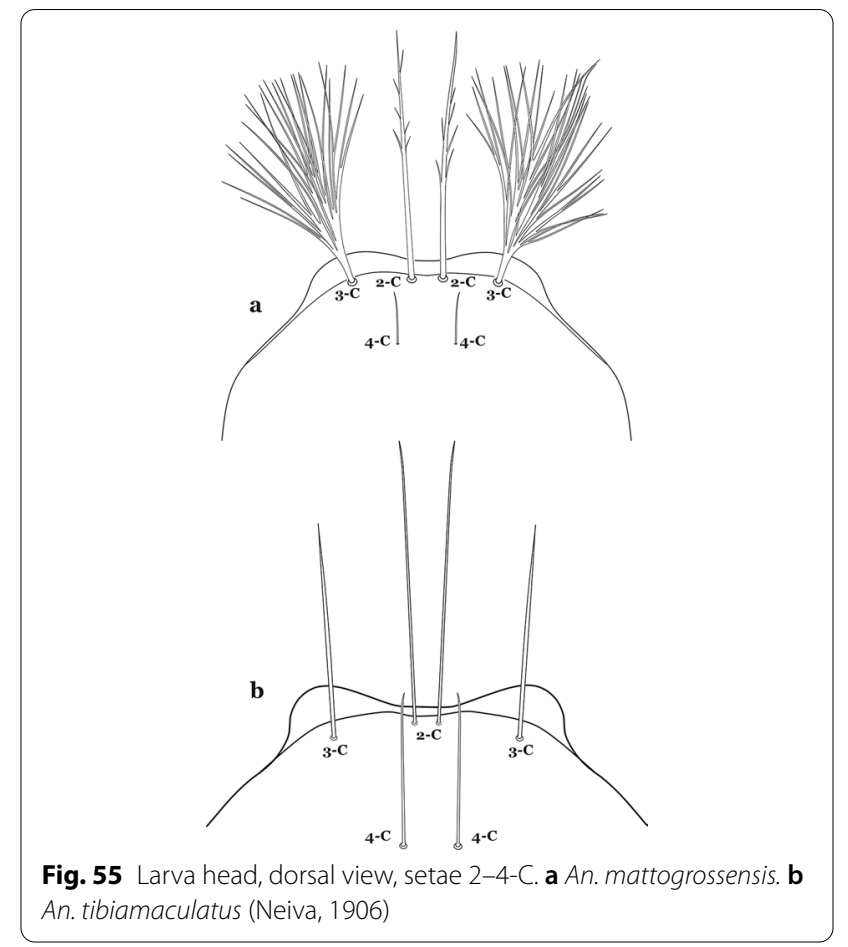

50a (49a) Seta 1-P fan-like (Fig. 56a)

An. mattogrossensis (in part)

50b Seta 1-P single or pinnate (Fig. 56b) .51

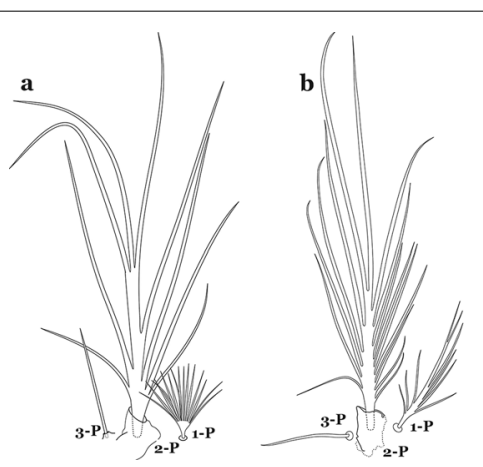

Fig. 56 Larval prothoracic setae 1-3-P. a An. mattogrossensis. b An. peryassui Dyar \& Knab, 1908

51a (50b) Seta 3-C strongly dendritic, branching begins near base, with more than 30 branches, shorter than 2-C; seta 4-C branching begins near base (Fig. 57a).... An. peryassui

51b Seta 3-C branching begins near mid-length (Fig. 57b); other characters, variable ...An. annulipalpis, An. shannoni \& An. vestitipennis 


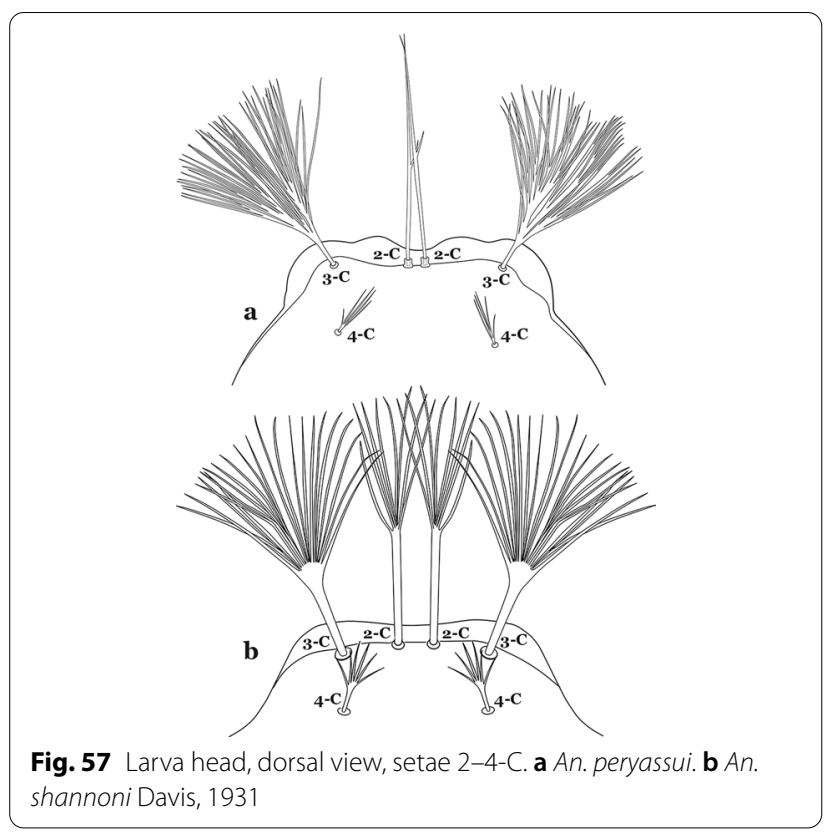

52a (49b) Seta 3-C shorter than 0.5 length of 2-C (Fig. 58a)......An. eiseni eiseni \& An. eiseni geometricus 52b Seta 3-C about 0.67 length of 2-C (Fig. 58b) An. tibiamaculatus

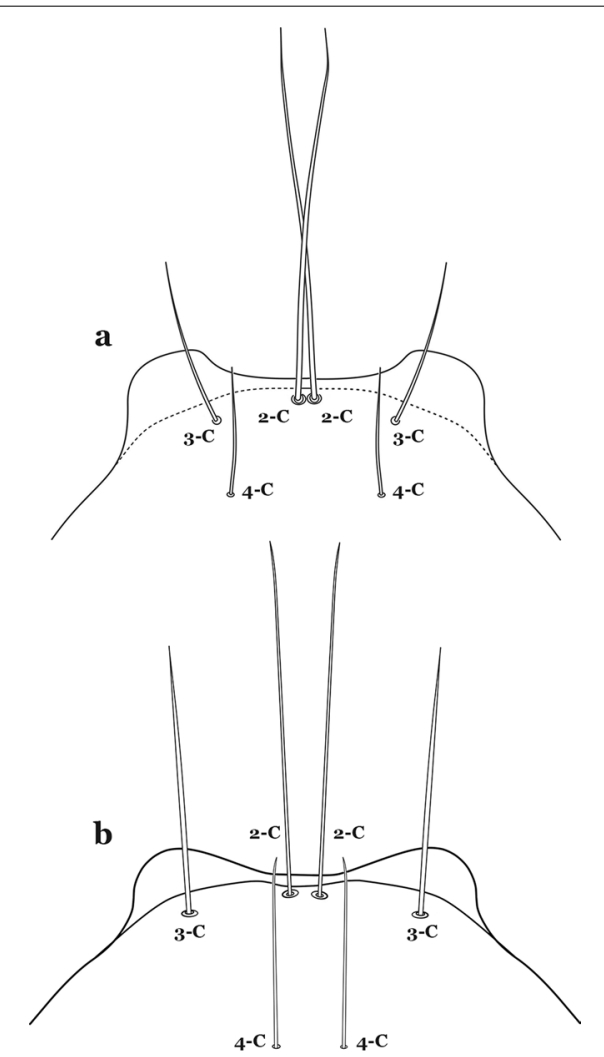

Fig. 58 Larva head, dorsal view, setae 2-4-C. a An. eiseni Coquillett, 1902. b An. tibiamaculatus (Neiva, 1906) 53a (47a) Seta 4-C very small or inconspicuous, 1-3-branched (Fig. 59a)

An. gilesi \& An. squamifemur

53b Seta 4-C long, single or multi-branched (Fig. 59b)

Seta 4-C long, single or multi-branched (Fig. 59.5

54a (53b) Setae 3,4-C single. An. pseudotibiamaculatus 54b Seta 3-C double; seta 4-C multi-branched (Fig. 59b) An. vargasi

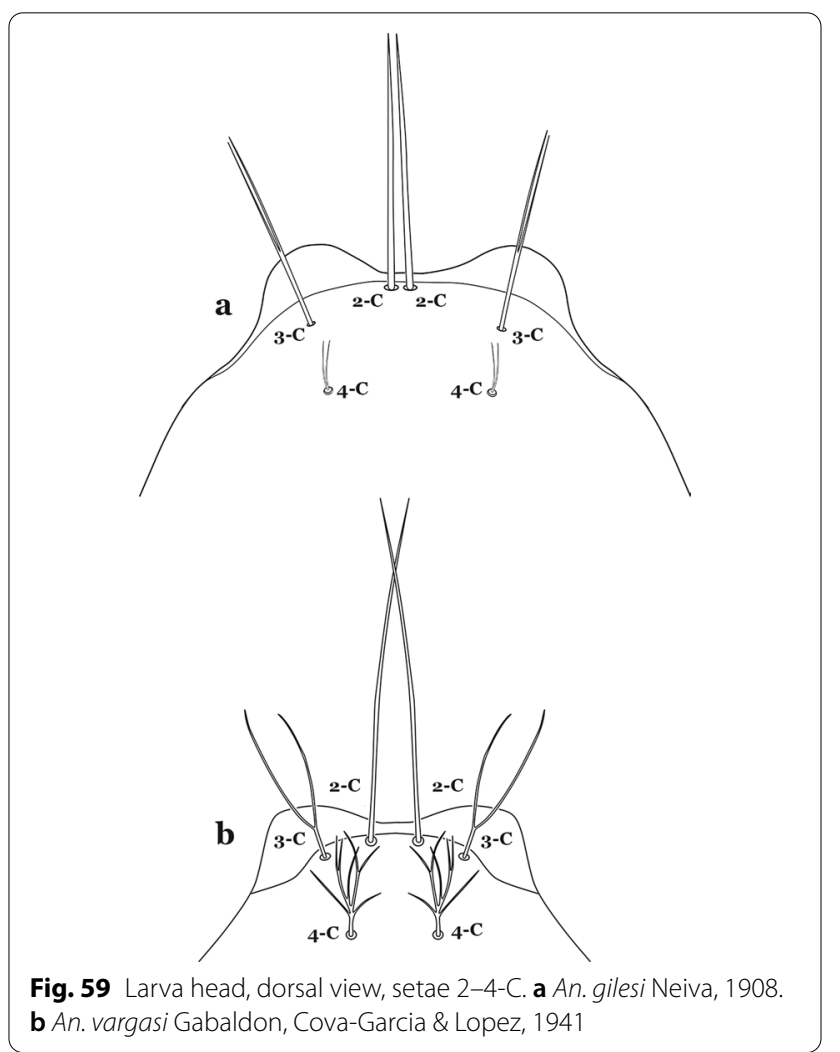

55a (46b) Seta 3-C single or double (Fig. 60a) ...............57 55b Seta 3-C multi-branched (Fig. 60b) . .58 


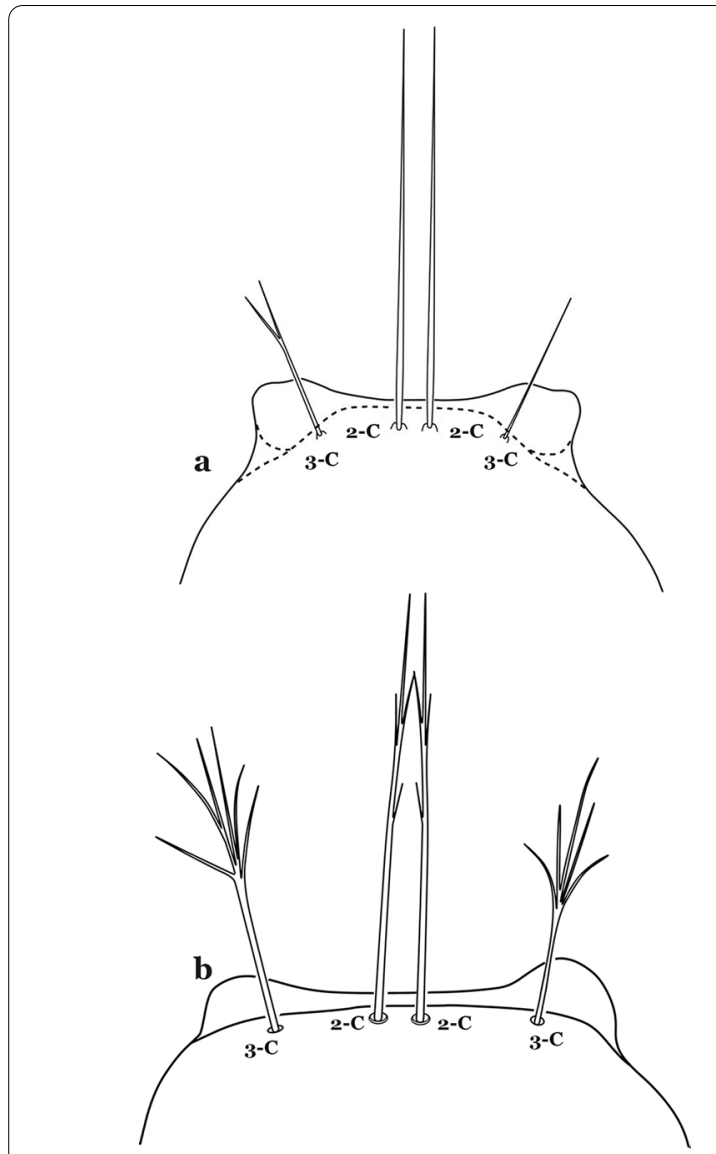

Fig. 60 Larva head, dorsal view, setae 2,3-C. a An. neomaculipalpus Curry, 1931. b An. calderoni

56a (55a) Seta 1-P single or with few branches (Fig. 61); setae 9-12-P single An. neomaculipalpus

56b Seta 1-P multi-branched; seta 9-P with few lateral branches, setae 10-12-P single...... An. apicimacula

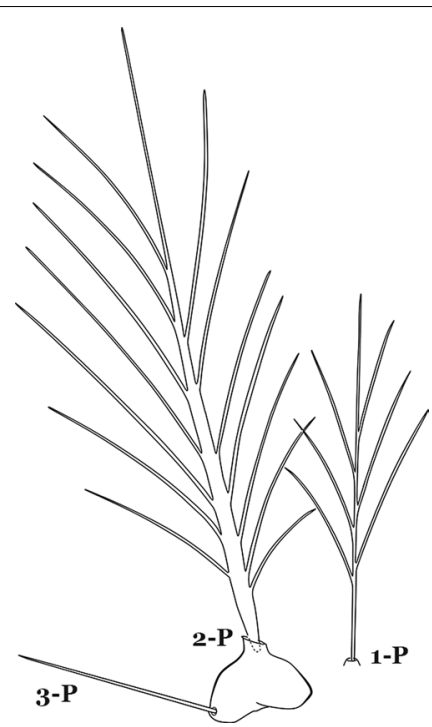

Fig. 61 An. neomaculipalpus, larval prothoracic setae 1-3-P

57a (55b) Seta 1-P branched distally, fan-like (Fig. 62a) An. mattogrossensis (in part)

57b Seta 1-P branched or pinnate (Fig. 62b) ..................58

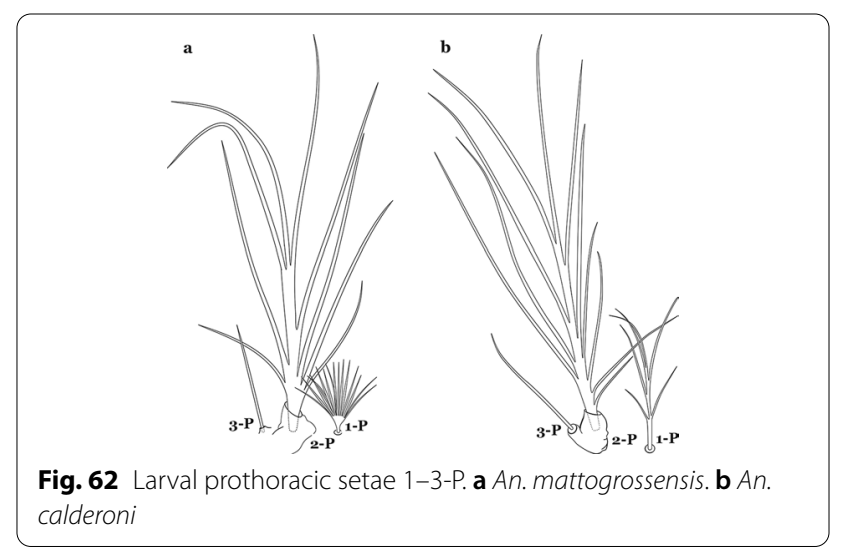

58a (57b) Setae 9-12-P all single (Fig. 63a) . .59

58b Setae 9-12-P with at least one branched (Fig. 63b) 

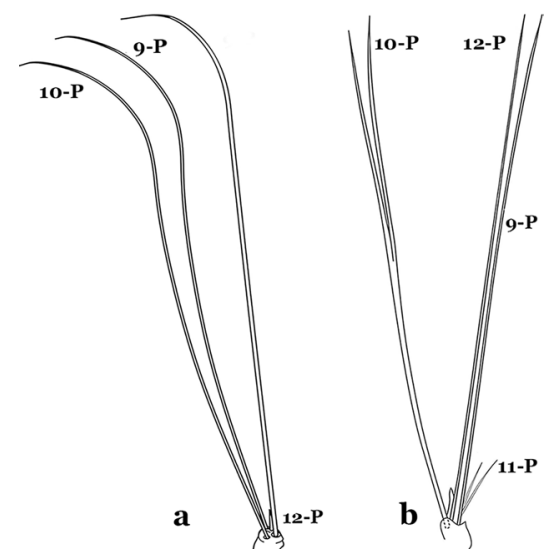

Fig. 63 Larval prothoracic setae 9-12-P. a An. anchietai Corrêa \& Ramalho, 1968. b An. calderoni

59a (58a) Seta 1-X inserted on saddle (Fig. 64a).

An. malefactor

59b Seta 1-X not inserted on saddle (Fig. 64b)... .60

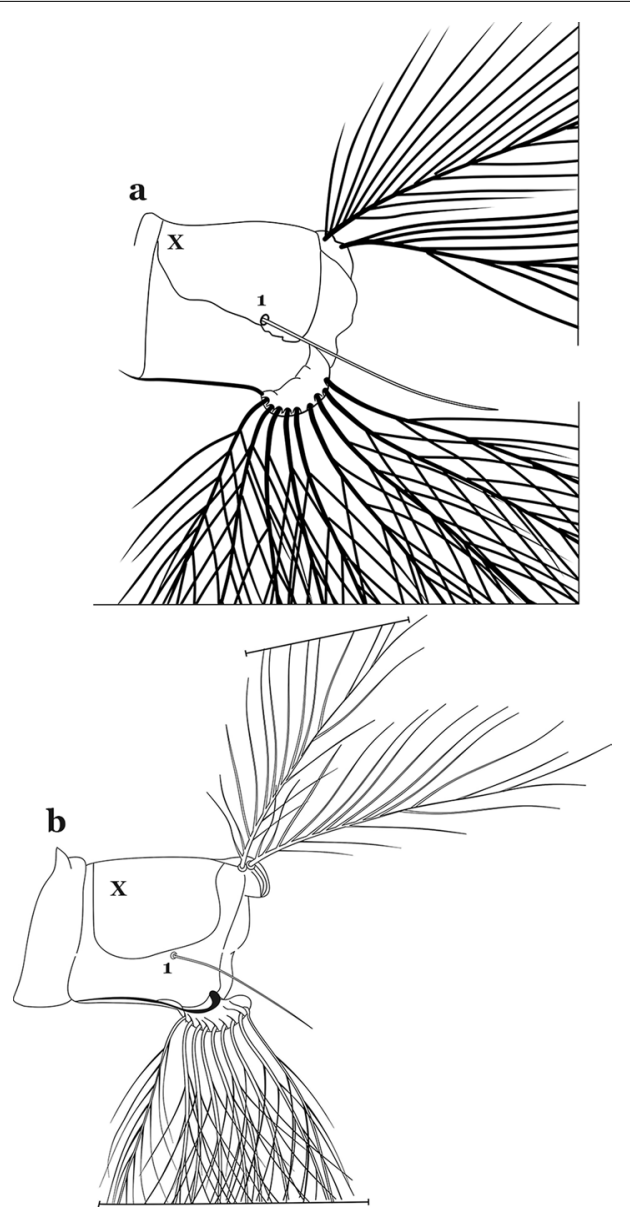

Fig. 64 Abdominal segment X. a An. malefactor Dyar \& Knab, 1907. b An. mediopunctatus (Lutz, 1903) 60a (59b) Seta 4-A long with lateral branches (Fig. 65a) ..........An. calderoni, An. guarao \& An. punctimacula

60b Seta 4-A short and asymmetrically branched (Fig. 65b)

.........An. costai, An. forattinii \& An. mediopunctatus
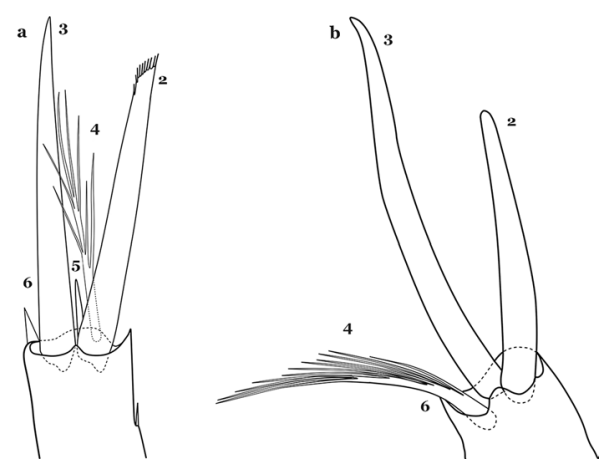

Fig. 65 Antennal setae 2-6-A. a An. calderoni. b An. mediopunctatus

61a (58b) Seta 3-C with few short branches originating on distal half of main stem (Fig. 66a) .....An. medialis

61b Seta 3-C with long branches originating on proximal half of main stem (Fig. 66b). .62

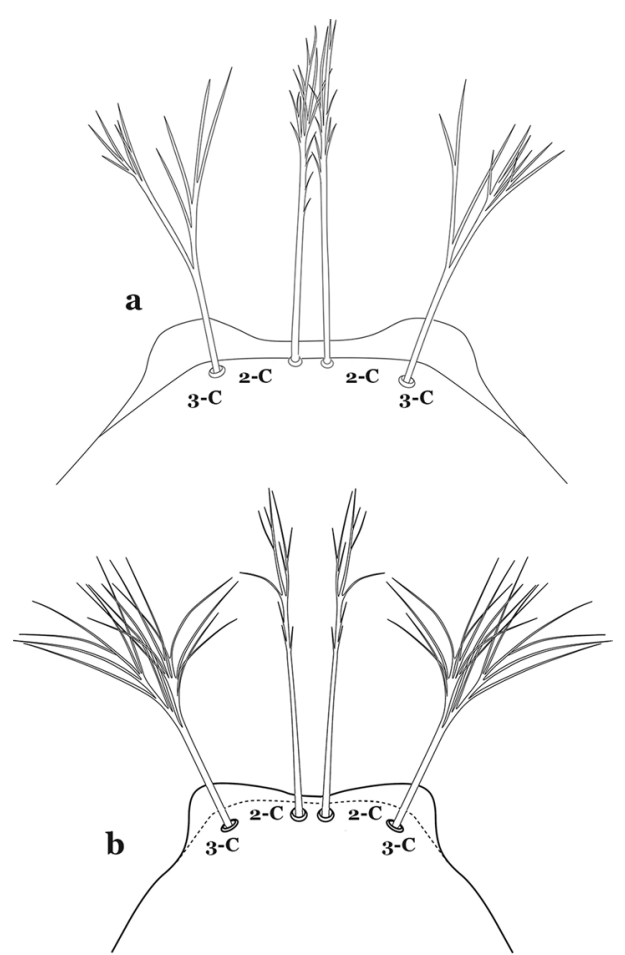

Fig. 66 Larva head, dorsal view, setae 2,3-C. a An. medialis Harbach, 2018. b An. fluminensis Root, 1927 
62a (61b) Seta 1-P single or double (Fig. 67a) An. maculipes \& An. anchietai

62b Seta 1-P with multiple branches (Fig. 67b) An. fluminensis
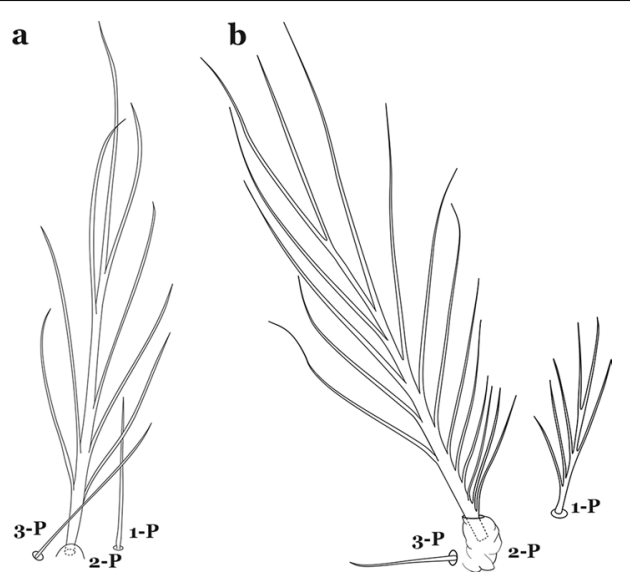

Fig. 67 Larval prothoracic setae 1-3-P. a An. anchietai. b An. fluminensis

\section{Conclusions}

Traditional and new characters have been employed in the key. Characters of the spiracular apparatus were found to be useful for the identification of certain species, such as those of the Strodei Group and the Myzorhynchella Section. The character states of abdominal seta $6-\mathrm{IV}, \mathrm{V}$ being single versus being branched has been largely employed to separate species of the Myzorhynchella Section from those of Nyssorhynchus. However, this character needs to be carefully considered because of variation in species of Myzorhynchella Section. In addition, in An. atacamensis and An. pictipennis this seta is slightly serrate at the edges. The variation in the character was included in the key to avoid inaccurate identification of the species of Nyssorhynchus as species of the subgenus Anopheles.

\section{Acknowledgements}

This work would not have been possible without the examination and permission for photographs of specimens from one of the major collections of mosquitoes in South America, repository of valuable reference specimens of multiple species of Anopheles of the Neotropical Region, including primary and secondary type-specimens, at the Coleção Entomológica de Referência da Faculdade de Saúde Pública, Universidade de São Paulo, Brazil (FSP-USP). We also thank the Museum of Entomology at the Universidad del Valle, Colombia, for allowing the use of photographic resources and preparing digital images of various parts of its entomological collection. MAMS extends her thanks to the Saúde Pública, Universidade de São Paulo, for their continued support for research projects and the logistics facility for the preparation and maintenance of thousands of specimens of the mosquito collection; and the Fundação de Amparo à Pesquisa do Estado São Paulo for continuous financial support that allowed the execution of hundreds of field sampling efforts for research in the systematics and ecology of mosquitoes (FAPESP Grants \#2014/26229-7; \#2011/20397-7; \#2005/53973-0; CNPq \# 301877/2016 to MAMS). RGO and NSC give special thanks to the Facultad de Ciencias Naturales y Exactas de la Universidad del Valle, Colombia, for continuous support and the logistics facility. Project Amazon Malaria Initiative (AMI) - Amazon Network for the Surveillance of Antimalarial Drug Resistance (RAVREDA) provided partial financial support with assistance from USAID and coordination with PAHO/WHO. We are in debt to Yvonne-Marie Linton (Walter Reed Army Institute of Research) and Bruce Harrison (in memoriam) for their thoughtful review of the first version of the identification keys, Caio Cesar Moreira, Faculdade de Saúde Pública, Universidade de São Paulo, for final editing of all illustrations, and Ralph E. Harbach (Natural History Museum, London, UK) for his thoughtful revision and valuable contribution for the manuscript, and Aneta Kostadinova for her suggestions, corrections, editorial edits that greatly improved the Part II. The activities undertaken at WRBU were performed in part under a Memorandum of Understanding between the Walter Reed Army Institute of Research (WRAIR) and the Smithsonian Institution, with institutional support provided by both organizations. The views expressed in this article are those of the authors and do not necessarily reflect the official policy or position of the U.S. Army, the Department of Defense, or the U.S. Government.

\section{Authors' contributions}

MAMS and RCW conceived the study. MAMS, RGO and RCW constructed the identification key. MAMS, RGO and NC prepared all illustrations. MAMS, RCW and $\mathrm{RGO}$ wrote the manuscript. All authors revised successive drafts of the key. All authors read and approved the final manuscript.

\section{Funding}

This study was funded by the Fundação de Amparo à Pesquisa do Estado de São Paulo (FAPESP) grant no. 2014/26229-7, CNPq grant no. 301877/2016-5 to MAMS; the Armed Forces Health Surveillance Board - Global Emerging Infectious Disease Surveillance (AFHSB-GEIS) [P0116_19_WR_05 and P0140_20_WR_05].

\section{Availability of data and materials}

Specimens used in the current study are deposited and available in the Coleção Entomológica de Referência, Faculdade de Saúde Pública, Universidade de São Paulo (FSP-USP), São Paulo State, Brazil, the US National Mosquito Collection, Smithsonian Institution, Washington, DC, USA (USNMC), and the

Facultad de Ciencias Naturales y Exactas de la Universidad del Valle, Colombia.

\section{Ethics approval and consent to participate}

Not applicable.

\section{Consent for publication}

Not applicable.

\section{Competing interests}

The authors declare that they have no competing interests.

\section{Author details}

${ }^{1}$ Departamento de Epidemiologia, Faculdade de Saúde Pública, Universidade de São Paulo, Avenida Doutor Arnaldo 715, São Paulo, São Paulo CEP01246-904, Brazil. ${ }^{2}$ Departamento de Biología, Universidad del Valle, A.A 25360 Cali, Colombia. ${ }^{3}$ Department of Entomology, Smithsonian Institution, National Museum of Natural History (NMNH), Washington, DC 20560, USA.

${ }^{4}$ Walter Reed Biosystematics Unit, Smithsonian Institution Museum Support Center, 4210 Silver Hill Rd., Suitland, MD 20746, USA. ${ }^{5}$ Walter Reed Army Institute of Research, 503 Robert Grant Avenue, Silver Spring, MD 20910, USA.

Received: 4 August 2019 Accepted: 8 August 2020

Published online: 18 November 2020

\section{References}

1. Sallum MAM, Gonzalez Obando R, Carrejo N, Wilkerson RC. Identification keys to the Anopheles mosquitoes of South America (Diptera: Culicidae). I. Introduction. Parasit Vectors. 2020. https://doi.org/10.1186/ s13071-020-04298-6. 
2. Cohen JM, Le Menach A, Pothin E, et al. Mapping multiple components of malaria risk for improved targeting of elimination interventions. Malar J. 2017; 16:459.

3. WHO. Guidelines for malaria vector control. Geneva: World Health Organization; 2019. https://www.who.int/publications/i/item/guidelines -for-malaria-vector-control.

4. Baird JK. Malaria control by commodities without practical malariology. BMC Public Health. 2017;17:590.

5. Harbach RE, Knight KL. Taxonomists' glossary of mosquito anatomy. Marlton: Plexus Publishing, Inc.; 1980.

6. Harbach RE, Knight KL. Corrections and additions to Taxonomists' Glossary of Mosquito Anatomy. Mosq Syst. 1982;13(1981):201-17.

7. Faran ME, Linthicum KJ. A handbook of the Amazonian species of Anopheles (Nyssorhynchus) (Diptera: Culicidae). Mosq Syst. 1981;13:1-81.

8. Forattini OP. Culicidologia Medica. Vol. II. Identificacão, Biologia, Epidemiologia. São Paulo: Publisher Edusp; 2002.

9. Sallum MAM, SchultzT, Wilkerson RC. Phylogeny of Anophelinae (Diptera, Culicidae) based on morphological characters. Ann Entomol Soc Am. 2000;93:745-75.

10. Greni SE, Demari-Silva B, de Oliveira TMP, Suesdek L, Laporta GZ, Sallum MAM. A multi-gene analysis and potential spatial distribution of species of the Strodei Subgroup of the genus Nyssorhynchus (Diptera: Culicidae). J Med Entomol. 2018;55:1486-95.
11. Foster PG, de Oliveira TMP, Bergo ES, Conn JE, Sant'Ana DC, Nagaki SS, Nihei S, Lamas CE, González C, Moreira CC, Sallum MAM. Phylogeny of Anophelinae using mitochondrial protein coding genes. R Soc Open Sci. 2017:4:170758.

12. Bourke BP, Oliveira TP, Suesdek L, Bergo ES, Sallum MA. A multi-locus approach to barcoding in the Anopheles strodei subgroup (Diptera: Culicidae). Parasit Vectors. 2013;6:111.

13. Sallum MA, Foster PG, Dos Santos CL, Flores DC, Motoki MT, Bergo ES. Resurrection of two species from synonymy of Anopheles (Nyssorhynchus) strodei Root, and characterization of a distinct morphological form from the Strodei Complex (Diptera: Culicidae). J Med Entomol. 2010;47:504-26.

14. Forattini OP, Sallum MA, Bergo ES, Flôres DC. Ultrastructure of eggs of Anopheles rondoni, Anopheles lutzii, and Anopheles parvus, three species of the subgenus Nyssorhynchus. J Am Mosq Control Assoc. 1998;14:256-65.

15. Sallum MA, Wilkerson RC. Description of the immature stages of Anopheles (Nyssorhynchus) rondoni (Neiva \& Pinto) (Diptera: Culicidae). Mem Inst Oswaldo Cruz. 1997;92:365-72.

\section{Publisher's Note}

Springer Nature remains neutral with regard to jurisdictional claims in published maps and institutional affiliations.
Ready to submit your research? Choose BMC and benefit from:

- fast, convenient online submission

- thorough peer review by experienced researchers in your field

- rapid publication on acceptance

- support for research data, including large and complex data types

- gold Open Access which fosters wider collaboration and increased citations

- maximum visibility for your research: over 100M website views per year

At BMC, research is always in progress.

Learn more biomedcentral.com/submissions 